Historic, archived document

Do not assume content reflects current scientific knowledge, policies, or practices. 



\section{Calculating Flame Spread on Horizontal and Vertical Surfaces}

Gamal N. Ahmed, Mark A. Dietenberger and Walter W. Jones

Building and Fire Research Laboratory

Gaithersburg, Maryland 20899

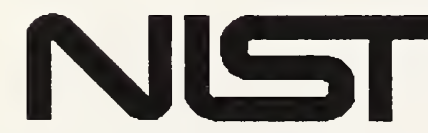

United States Department of Commerce nology Administration

QC $\quad$ nal Institute of Standards and Technology

100

.056

1994

\#5392 



\section{Calculating Flame Spread on Horizontal and Vertical Surfaces}

Gamal N. Ahmed, Mark A. Dietenberger and Walter W. Jones

April 1994

Building and Fire Research Laboratory

National Institute of Standards and Technology

Gaithersburg, MD 20899

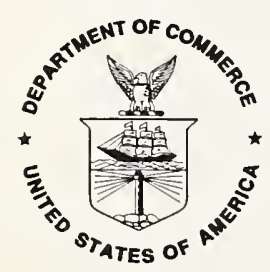

United States Department of Commerce

Ronald H. Brown, Secretary

Technology Administration

Mary L. Good, Undersecretary for Technology

National Institute of Standards and Technology

Arati Prabhakar, Director 



\section{CONTENTS}

1. INTRODUCTION

2. FEATURES OF THE FLAME SPREAD ALGORITHM 4

3. SCALING PROCEDURES FOR BENCH SCALE DATA 7

3.1 Ignition and Flame Spread Properties 8

3.2 Scaling of Heat and Mass Release Rates 16

3.3 Local Convective Heat Flux and Fuel Pyrolysis Rate 22

3.4 Scaling of Combustion Products and Soot 23

3.5 Heat and Mass Release Rates of Flame 24

4. THERMAL RADIATION ANALYSIS 29

4.1 Hottel's Zonal Thermal Radiation Analysis 29

4.2 Volume Emissivities Due to Soot, $\mathrm{H}_{2} \mathrm{O}$, and $\mathrm{CO}_{2}$

4.3 Evaluation of Hottel's Exchange Areas 31

5. GEOMETRY CONSTRUCTION AND INPUT DATA 33

5.1 Modification to FAST Database File 33

5.2 Panel Database File $\quad 34$

5.3 Bench Database File $\quad 36$

5.4 Cone Calorimeter Database File 38

6. APPLICATIONS AND RESULTS $\quad 39$

6.1 Burning Wall in a Single Compartment 39

6.2 Burning Horizontal Panel in a Single Compartment 39

6.3 Effect of Door Opening on Burning Wall in a Single Compartment 39

6.3.1 Effect of Door Width 39

6.3.2 Effect of Door Height 40

7. CONCLUSIONS 43

8. NOMENCLATURE 46

10. REFERENCES 49

APPENDIX A: Sample Input Database Files $\quad 52$

A.1 Wall Data Input File to Fast (WALL.DAT) 52

A.2 Panel Database File as Input (PANEL.DAT) 52

A.3 Bench Database File as Input (FRPUHO.DAT) 52 


\section{FIGURE CAPTIONS}

Figure 1. Structure of flame spread model and database.

Figure 2. Construction of $\mathrm{q}_{\mathrm{k}}$ and $\mathrm{s}_{\mathrm{k}}$ from heat flux distribution

fixed ahead of the flame front.

Figure 3. Schematic of simulated flame spread

Figure 4a. Original data of heat release flux vs time for LO fabric/FR PU foam. 18

Figure 4b. Corresponding scaled heat release fluxfor LO fabric/FR PU foam. 18

Figure 5a. Original data of fuel release flux vs time for LO fabric/FR PU foam. 19

Figure 5b Corresponding scaled fuel release flux versus scaled timefor LO fabric/FR PU foam material

Figure 6a. Processed data of $\mathrm{CO}$ and $\mathrm{CO}_{2}$ mass ratio for $\mathrm{LO}$ fabric/FR PU foam.

Figure $6 \mathrm{~b}$ Processed data of $\mathrm{CO}$ and $\mathrm{CO}_{2}$ mass ratio versus scaled time for $\mathrm{LO}$ fabric/FR PU foam 25

Figure 7a. Calculated soot to fuel mass ratio vs time for LO fabric/FR PU foam. 26 Figure $7 \mathrm{~b}$ Calculated scaled soot mass flux versus scaled time for LO fabric/FR PU foaml

Figure 8 Geometry of the room of fire origin and the global xyz-coordinates.

Figure 9 Initial position of a panel $(1.0 \times 1.0 \times 0.02)$ at different fire positions, LFPOS 35

Figure 10 Sequences of panel positions in response to the effect of the angles of rotation $(\phi, \theta, \psi)$

Figure 11. Initial and final positions of the panel $(1.0 \times 1.0 \times 0.02 \mathrm{~m})$ in the room of fire origin $(4.0 \times 12.0 \times 3.0 \mathrm{~m})$.

Figure 12. Flame spread contours on a thick horizontal panel $(1.0 \times 1.0 \times 0.1 \mathrm{~m}) \quad 40$ Figure 13 Flame spread contours on a thin wall $(3.0 \times 2.0 \times 0.02 \mathrm{~m})$ as a function of time.

Figure 14. Flame spread contours on a full size thin wall $(3.8 \times 2.9 \times 0.02 \mathrm{~m})$ as a function of time.

Figure 15. Effect of door opening width on the depth of hot gas layer in the room of fire origin as a result of burning of a full size thin wall.

Figure 16. Effect of door opening height on the depth of hot gas layer in the room of fire origin as a result of burning of a full size thin wall.

Figure 17. Effect of door opening height on the pyrolysis rate in the room of fire origin as a result of burning of a full size thin wall. 


\title{
Calculating Flame Spread on Horizontal and Vertical Surfaces
}

\author{
Gamal N. Ahmed ${ }^{1}$, Mark A. Dietenberger ${ }^{2}$ and Walter W. Jones \\ Building and Fire Research Laboratory \\ National Institute of Standards and Technology
}

The flame spread model described in this paper is a new algorithm which provides the capability to calculate a self-consistent fire based substantually on bench scale fire data. The flame spread model simulates object fire growth and burnout of a slab in a room and produces acceptable predictions of the spread of fire, smoke and production of both toxic and nontoxic gases. The purpose of the flame spread model is to allow a fire to grow realistically, possibly making a hole in the material surface. This is one mechanism for barrier penetration. The algorithm is based on empirical data, gathered from standard test apparatus, including the Cone Calorimeter and the LIFT (lateral ignition flame spread test method). By basing the pyrolysis on test methods, we avoid the practical difficulties associated with an explicit calculation of radiation blocking and material charring. The objective of including the flame spread model is to predict the accelerative growth of a fire from ignition to a peak value and then the gradual termination normally seen in a fire. The intent of the project was to develop an algorithm which could be utilized in a complete model of a fire in a building. The three-dimensional aspects of the flame spread model include: first, panels made of combustible materials with different thicknesses and at various orientations; second, flames of two basic types, pool fire and purely wall fire; third, a radiation heat exchange between objects, flames, and gases. The pool fire has a flame spreading polygon on a horizontal panel and the wall fire is used either for inclined or vertical panels.

\section{INTRODUCTION}

The Fire Hazard Methodology (HAZARD I) was published by the National Institute of Standards and Technology (NIST) in the Summer of 1989. It is a methodology designed to allow fire protection engineers, architects and others to consider the implications of unwanted fire in a building. The first release was a prototype. Its focus was primarily to incorporate the research which had already been done at NIST and elsewhere into a relatively small reference guide, along with the computer software which implemented this work. Since then, the Building and Fire Research Laboratory has directed much of its research into improving and enhancing this product. Much of the applied fire research now being performed at NIST is connected with the Hazard Methodology, and adds to its capability. The intention is to make the research efforts available to industry as early as possible, as well as provide a focus for the research.

The evolution of compartment fire numerical models in recent years has included new models of the fire source. Previous fire simulation was achieved by using free burn data to specify a fire growth curve. The implication of using free burn data is that the

${ }^{1}$ Fire Research Engineer, Portland Cement Association (PCA), Skokie, Illinois

${ }^{2}$ Research General Engineer, USDA Forest Products Laboratory, Madison, Wisconsin. 
fire is not affected by its surroundings. There are two effects which are important, however. The first is the constraint imposed by available oxygen and the second is the enhanced pyrolysis rate engendered by additonal radiation from the room in which the fire resides. Although recent improvements in fire models have included the oxygen constraint, currently no model calculates a self-consistent fire with radiative feedback.

HAZARD I is based on our current understanding of fire related phenomena. An example is the requirement for a specified fire. In essence, the data used for the fire specification comes from free-burn data obtained in a furniture calorimeter or similar device. The fire can be constrained by a lack of oxygen, but is not affected by radiative feedback. There are some aspects of fires about which little is known, for example, the detailed mechanism of the pyrolysis at a material surface is not yet completely understood.

The FAST (fire and smoke transport) model [1] is an example of a model which utilizes the distinct gas zones concept. The basic predictive equations are derived from the laws of conservation of the mass, momentum and energy. There are usually two zones, or control volumes, per compartment. The two zones are referred to as upper and lower respectively. Transfer can occur from zone to zone or compartment to compartment in a fire driven environment. These equations are written so that the actual physical phenomena which affect the environment are couched as source terms and appear on the right-hand side. Such a formulation allows the greatest flexibility in adding, modifying, or deleting terms which are appropriate to the problem being solved. This model for fire growth and smoke spread includes a constraint on the burning rate, as would be predicted from the free burn data, based on the available oxygen. However, it does not included the enhanced pyrolysis that is engendered by the radiation from a developing smoky layer in a fire or the surrounding boundaries, such as a wall, ceiling or floor. The flame spread model (FSM) discussed in this paper is couched simply as another algorithm which can then be inserted into FAST. It then provides source terms for the radiative heat transfer, plume mass rate and heat and mass release rates which will close this gap.

Most compartment fires involve burning of items made of finite thickness combustible materials or made of an inert substrate covered with thin, combustible materials. The burning of these items can cause structural failure or collapse of the walls, room dividers, ceiling, or floor, which may lead to a catastrophic threat to the building and occupants. The structural integrity of a room divider will, for example, be affected by the burn-through process, while that of a glass wall depends on the amount of radiative heat applied. Modeling the burn-out process and the distribution of applied radiative heat as a function of time are some of the features of the flame spread model to be discussed in the next section.

After the description of the salient features of the algorithm in the next section, further details are provided in three additional sections: first, the method of scaling of the bench scale data for use in subsequent analysis; second, the detailed thermal radiation 
analysis using Hottel's Zonal method; and third, the geometrical construction of the combustible item and additional input to the flame spread model. The final sections are the application and results of using the model in particular applications, and our conclusions about its applicability and usefulness. 


\section{FEATURES OF THE FLAME SPREAD ALGORITHM}

During the past few years, an empirical model has been developed [2] which uses experimental data to describe the pyrolysis mechanism. One purpose of the flame spread model is to allow a fire to grow realistically, possibly making a hole in the material surface. This is one mechanism for barrier penetration. The flame spread model is based on empirical data, gathered from standard test apparatus, including the Cone Calorimeter [3] and the LIFT (lateral ignition flame spread test method) [4]. By basing the pyrolysis prediction on empérical test methods, we avoid the practical difficulties associated with an explicit calculation of radiation blocking or charring. The type of output available from this model includes a contour map of the flame front, which shows the model has verisimilitude with fires that one actually sees. It has been simplified to allow it to be included in the HAZARD model. Until now, the Hazard Methodology relied on fires based on full scale, free burn data. The FSM is a new algorithm which provides the capability to calculate a self-consistent fire based only on bench scale fire data. The flame spread model simulates object fire growth and burnout of a slab in a room and produces acceptable predictions of the spread of fire, smoke and production of both toxic and nontoxic gases. Such an analytical tool has potential for reducing the number of full scale tests and for providing the fire protection community with improved predictive capability for fire hazard, particularly when evaluating new materials in a new environment.

The objective of including the flame spread model is to predict the accelerative growth of the fire from ignition to a peak value and then the gradual termination normally seen in a fire. The three-dimensional aspects of the flame spread model include: first, panels made of combustible materials with different thicknesses and at different orientations; second, flames of two basic types, pool fire and purely wall fire. The former has a flame spreading polygon on a horizontal panel. The latter is used either for inclined or vertical panels; third, a radiation heat exchange between objects, flames, and surrounding ambient. The latter physics is the most time consuming of the numerics of the model.

The dynamic features of the model include: (a) flame spreading in any (and all) direction(s) on a panel, (b) the varying mass and heat release rates which are found as a result of the scaled burning history of matierals on the panel, and (c) the temperature changes of surface elements, walls, and gas layers. The reliance of the model on effective scaling of the Cone Calorimeter data and of the flame spreading data, and its validation with the full scale fire tests is an important feature. Use of these test results allows us to avoid some of the theoretical difficulties associated with radiation blocking and charring. This also allows us to make a firm connection between bench scale tests and full scale predictions. This will be important for establishing the usefulness of bench scale testing as a substitute for full scale tests.

The model tracks the temperature and thickness of a panel as a function of 
position. When the predicted surface temperature at an element over a time step exceeds a critical temperature, the model will redefine certain parameters to initiate the material burn history region at the surface element. If the critical temperature is the ignition temperature (the thermal ignition is assumed to occur when the surface element temperature reaches the ignition temperature), then the surface temperature is set to the burning temperature, the remaining burning time in the time step is calculated, the surface element is labeled as burning, and the flame spread region is defined to include the surface element. If the critical temperature is the pyrolysis temperature and less than the ignition temperature, then the burning time increment within the time step is calculated and a pyrolysis state is defined for the surface element. If a surface element is already labeled burning or pyrolyzing, and its net surface heat flux becomes negative, then the burn history is frozen and a surface temperature decrement over the time step is calculated instead.

The procedure used in simulating flame spread is as follows. A panel is divided up into rectangular surface elements. The net surface heat flux and the surface temperature is computed as a function of time at the midpoint of each element. Ignition can be piloted or not. If there is an ignition source, then the user indicates piloted ignition by defining the time of ignition at one or more elements. The simulation of ignition at a point (piloted or otherwise) is implemented by constructing a small octagonal burning area at the location specified. An octagon with its vertices moving outward is used as a practical representation of the flame spread region originating at a piloted ignition point. An elongated polygon is used for a line ignition source. Flame spread is simulated by moving the vertices of the burning polygon in a normal outward direction over an incremental distance in an incremental time period. The magnitude of the flame spread vector is then the flame spread rate multiplied by the time step, unless it is cut short by intersection with the panel edge. The flame spread rate itself is a function of preheated element temperature, orientation, ignition temperature, and thermal properties.

The accelerative growth of the flame heat release rate is due to two main competing factors: the rate of increase of number of burning surface elements and the rate of increase of the surface radiative heat flux. Eventually, a peak value of the flame heat release rate is reached and then its rate of decrease is controlled by burnout of the surface elements. While the surface is burning, the local burning rate will result in materiai recession. During recession the burnout boundaries are advanced. Thus, the mass loss parameter is a direct indication of the wall's or the panel's deterioration due to fire, and will lead to the determination of the length of time it will take for the element to develop a hole. This, in turn, will provide a tool for evaluating the effectiveness of the member as a fire barrier. The receding depth of the burning material is a function of the burn history, the original material thickness, and the quasi-stoichiometric ${ }^{3}$ heat release. If all the surface elements in a wall are burning, then the flame spread polygon is shifted to keep in planar contact with a nearest burning surface element. When the flame spread polygon is finally shifted by an amount equal to the original combustible thickness of the

${ }^{3}$ Please see section 3.2 for a discussion of the meaning of this term. 
panel, the wall or panel no longer supports pyrolysis or combustion.

A model of flame spread must deal with a three-fold coupling between the physical processes of fuel pyrolysis, soot production in the fire, and the thermal radiation due to the presence of the fire. It is also clear that additional, but different, interactions are involved in the thermal heating of surfaces, the spread of the fire base, and the burning history of a surface element. The thermal radiation field is the common denominator in the coupling between all physical processes. As these variables are calculated as a function of time, the solution accuracy, stability, and efficiency are maintained by analyzing the nature of the interaction between the variables describing the physical processes. Some variables, such as, virgin surface temperature response, flame spread, and burn history all changed slowly enough with time and are sufficiently weakly coupled to each other so that they could be integrated explicitly with time. The other set of variables, i.e., the fuel pyrolysis rates, the soot production, and the flame size along with the thermal radiation are interact strongly and involve very short time frames. These variables are solved in a convergent iterative scheme.

In the present implementation, the numerical solution of this phenomenon is timesplit, or decoupled, from the flow equations. The nominal sub-scale time step in FAST is 0.2 second. As a practical matter, however, we have found that a sub-scale interval of 5.0 seconds is adequate. Since flame spread is very computationally intensive (mainly due to thermal radiation calculations), we use the latter time step. Also, there is a coupling of the physical processes between that of FAST and the flame spread model. FAST solves a system of ordinary differential equations (ODEs) to provide the pressure, upper and lower gas layer temperatures, zone gas layer volume, and chemical specie masses as a function of time. These ODEs for each zone require as input the current values of the source terms, which are the thermal radiative heat rate, surface convective heat rate, fire plume mass rates, venting mass rates, and fire heat and mass release rates. Of these terms, the flame spread model provides current values of the thermal radiative heat rate, fire plume mass rates, and fire heat and mass release rates. The flame spread model requires as input the current values of pressure, temperature, volume, and chemical specie mass of each zone in the fire source room. 


\section{SCALING PROCEDURES FOR BENCH SCALE DATA}

The bench scale data required by the flame spread model are derived from the Cone Calorimeter and LIFT apparatus. To utilize the Cone Calorimeter data and the LIFT apparatus data, a model of a physical process must be analyzed in two phases. The first phase is processing of the basic database to derive material parameters for flame spread and to derive scaling variables corresponding to the Cone Calorimeter measured variables. In particular, we are concerned with pyrolysis and heat release rates as a function of the radiation field. The second phase uses the processed data from phase one as input to the predictive formulae for the various physical processes.

As illustrated in Figure 1, the first type of data consists of the material parameters for ignition and flame spread. The basic flame spread data typically consists of time to ignition and of the flame spread rate on a horizontal or vertical sample under varying irradiances. The formulae for thermal ignition and flame spread rate are fitted to these data to derive the corresponding material parameters.

\section{DERIVED DATABASES}

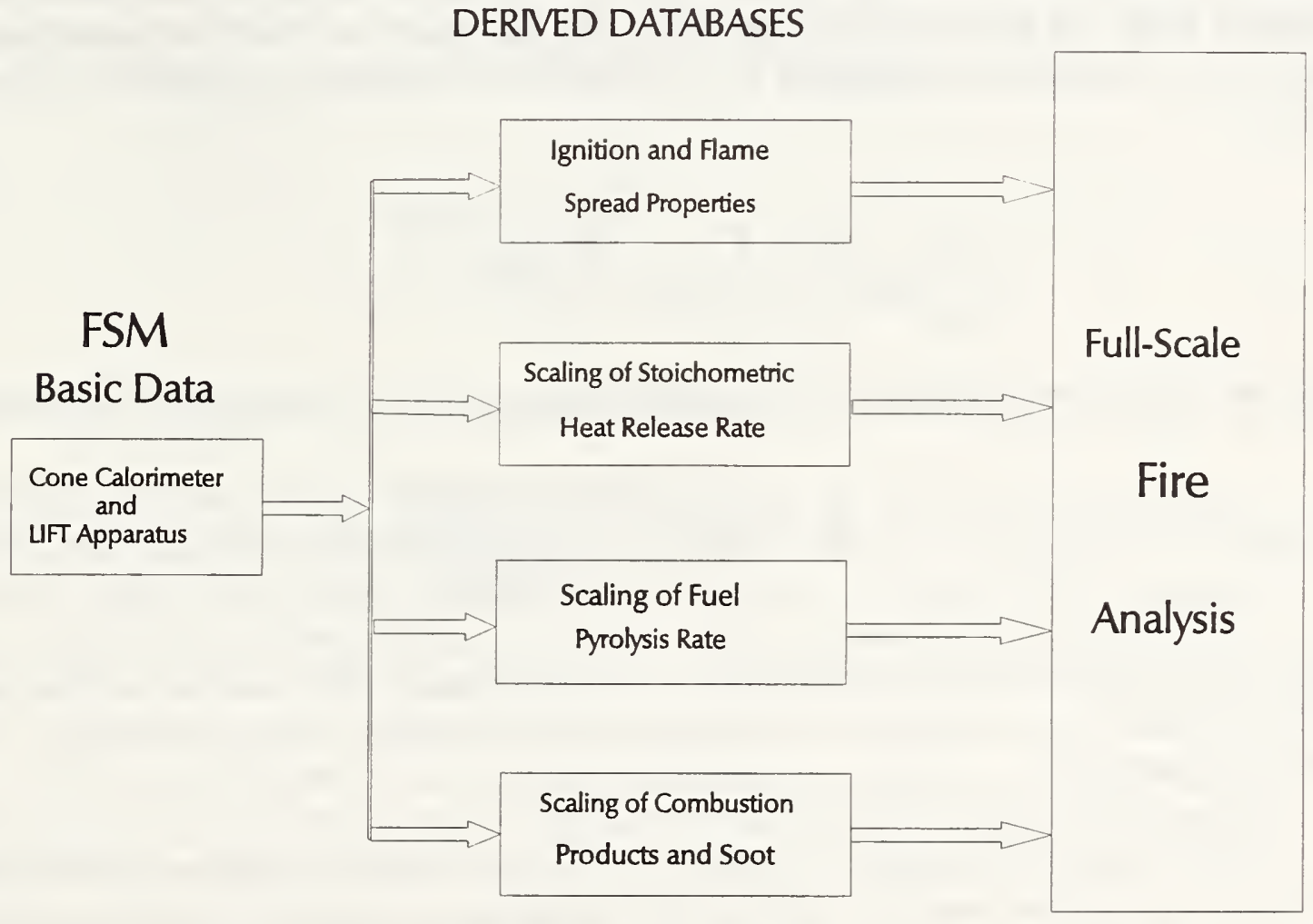

Figure 1. Structure of flame spread model and database.

The second type of derived data needed is the scaling of heat and mass release 
rates as functions of material burn history. The three constants for scaling the basic heat and mass release rates are the scaled surface heat flux constant, the first scaling parameter for time stretching, and the second scaling parameter for time stretching (as explained in section 3.2). They can be determined iteratively by plotting of the scaled data at several irradiances.

The last set of derived data includes the scaling of combustion products and of soot mass fractions as a function of burn time. The derived soot parameters, the maximum soot absorption coefficient and the specific soot extinction areas, are treated as constants, but should eventually be obtained as a function of material burn history. These parameters are used in the formulae to calculate the soot mass fraction and the soot extinction area in the fire plume as a function of burn time.

\subsection{Ignition and Flame Spread Properties}

In an earlier study [2], the time to ignition and the flame spread rate properties of a fabric/foam cushion composite and of PMMA were determined. The fabric/foam cushion behaves as a thermally thin material and the PMMA behaves as a thermally thick material. These are the examples that will be used for illustrating the difference between thermally thick and thermally thin materials, and the equations which are appropriate in each case. The surface temperature of a thermally thin material is evaluated by the formula,

$$
T_{s}=T_{o}+\int_{o}^{t} \frac{q_{s}(t-\tau) d \tau}{\rho c \delta}
$$

while the surface temperature of a thermally thick material is evaluated by the formula,

$$
T_{s}=T_{o}+\int_{o}^{t} \frac{q_{s}(t-\tau) d \tau}{\sqrt{\pi k \rho c \tau}}
$$

The former assumes that the temperature is constant through the material and the latter that the thermal wave continues to propagate into the material without reaching a farside boundary condition.

The net surface heat flux, $\mathrm{q}_{\mathrm{s}}$, due to net radiative heating and convective cooling is the heat load on the material. The surface temperature response of the thermally thin material is mediated by the characteristic thermal thickness, $\rho \mathrm{c} \delta$, while that of the thick material is mediated by the thermal inertia, k $\rho$ c. Assuming a constant irradiant flux and linearized heat transfer coefficient for radiant and convective cooling, the above equations have analytical solutions of surface temperature versus time [2]. Using the curve fits of the time to ignition versus irradiance flux of various materials from references [4] and 
[5], the values of the ignition temperatures and both the effective thermal thickness of the fabric/foam cushions and the thermal inertia of the PMMA can be derived [6].

There are three terms in the net surface heat flux, the first from radiation, the second from convective flow and the third from reradiation. The net radiative heat flux is obtained from the thermal radiation model and the convective heat flux is obtained from the empirical relationships for natural convection. The radiative heat transfer is a combination of radiation from the surroundings (provided by the system model) and the flame itself. These two sources are summed by the FSM and then reradiation from the material is subtracted off. Since the net surface heat flux is obtained from the flame spread model rather than prescribed by the Cone Calorimeter, eqs Figure 1 and Figure 1 are integrated numerically. The form used in the model for each case is discussed below, first the thermally thin (fabric) and then the thermally thick (PMMA) case.

Assuming that the irradiance is constant and that the radiative and convective heat fluxes are functions of surface temperature at any time increment, the surface temperature predictor for thermally thin materials can be obtained from eq Figure 1 and for thermally thick materials from eq (2). The approximate analytic solution to these two equations are

$$
T-T_{\infty}=\left(\frac{q_{r i}}{h}\right)\left(1-\exp \left(-\frac{h t}{\rho c \delta}\right)\right)
$$

and

$$
T_{s}-T_{\infty}=\left(\frac{q_{r i}}{h}\right)\left(1-\exp \left(\frac{h^{2} t}{k \rho c}\right) \sqrt{\operatorname{erfc}\left(\frac{h^{2} t}{k \rho c}\right)}\right.
$$

In these derivations, $T_{\infty}$ is the gas layer temperature, $T_{0}$ the initial temperature of the surface, and $T_{\text {eq }}$ is the temperature that the surface would be at steady state. These two equations suffer from being computationally intensive. A better form is found if we assume that the $T_{0}$ is that at time $(t)$, and we wish to know the surface temperature at time $(\mathrm{t}+\Delta \mathrm{t})$.

For the thin material, the resulting heat balance equation, eq. (3), can be linearized and solved analytically to approach the equilibrium surface temperature exponentially as $[2,6]$,

$$
T_{s}(t+\Delta t)=T_{e q}+\left(T_{s}(t)-T_{e q}\right) \exp [-h \Delta t /(\rho c \delta)]
$$

where 


$$
T_{e q}=\left(q_{r i} / h\right)+T_{\infty}=\left[q_{r i}(t)+h_{r} T_{s}(t)+h_{c} T_{\infty}(t)\right] / h
$$

and

$$
h=h_{r}+h_{c} \approx 4 \in \sigma T_{s}(t)^{3}+h_{c}
$$

where $h_{c}$ is the convective heat transfer and $T_{\infty}(t)$ is the current ambient temperature. The heat flux terms are: $\mathrm{q}_{\mathrm{ri}}(\mathrm{t})$ is the net radiative surface heat flux from external sources, $\mathrm{q}_{\mathrm{r}}(\mathrm{t})$ is the net radiative surface heat flux and $\mathrm{q}_{\mathrm{s}}(\mathrm{t})$ is the net surface heat flux (radiative plus convective).

For thermally thick material, the numerical integration of eq (2) for thermally thick materials is more difficult because of the spatial variation of the temperature within the material. The analytic form is not a viable alternative. The numerical integration of eq Figure 1 was effectively addressed in Reference [7] with the result,

$$
\begin{aligned}
T_{s}(t+\Delta t)=T_{\infty} & +\frac{T_{s}(t)-T_{\infty}}{\sqrt{1+9.65 p(t+\Delta t) \Delta t}} \\
& +\left[q_{s}(t)+q_{s}(t+\Delta t)\right] \cdot \sqrt{\frac{\Delta t}{\pi k \rho c}}
\end{aligned}
$$

where

$$
p(t+\Delta t)=q_{s}(t+\Delta t) / \int_{o}^{t+\Delta t} q_{s}(\tau) d \tau \quad \text { for } \quad T_{s}<T_{\infty}+5
$$

and

$$
p(t+\Delta t)=\ln \left[q_{s}(t+\Delta t) / q_{s}(t)\right] / \Delta t \quad \text { for } \quad T_{s}>T_{\infty}+5
$$

To apply these equations to the flame spread model, eq (8) predicts $T_{s}(t+\Delta t)$ by setting $\mathrm{q}_{s}(t+\Delta t)$ to $\mathrm{q}_{s}(t)$. Then the net surface heat flux for the next time step is calculated and eq (8) can be used to correct the predicted surface temperature. The limit on the surface temperature value is the equilibrium temperature, $T_{\text {eq }}$, given in eq (6).

There are two critical temperatures, the values for pyrolysis and ignition. When the predicted surface temperature at a surface element over a time step exceeds one of these critical temperatures, the model will redefine certain parameters to initiate the material burn history, a burning region, or both, at the surface element. If the critical 
temperature is the pyrolysis temperature and less than the ignition temperature, then the incremental burning time in the time step is calculated and a pyrolysis state is defined for the surface element. If the critical temperature is the ignition temperature, the surface temperature is set to the burning temperature. Then the incremental burning time in the time step is calculated, the surface element is labeled as burning, and the flame spread region is defined with the surface element. If a surface element is already labeled burning or pyrolyzing and also the net surface heat flux, $\mathrm{q}_{\mathrm{s}}$, becomes negative, then the burn history is frozen and a surface temperature decrement over the time step is calculated instead.

One approach to modeling flame spread is to define a surface element ignition state when the calculated surface temperature reaches a specified ignition temperature. The heat transfer from the anchored diffusion flame to the heated virgin surface would need to be calculated. This approach becomes impractical when we consider the small heating length derived in the deRis [8] model for flame spreading in opposed flow. That is, it is not practical to construct surface elements smaller than millimeters in order to resolve properly the heating from a diffusion flame which is anchored to the surface. Thus, there must be new ways of applying the classical solutions of flame spread to our problem. Many studies of flame spread consider the deRis [8] classical solutions for the opposed flow spread rate over both thermally thin and thick materials due to the heating from the diffusion flame anchored at the pyrolysis front. Recently the effect of finite chemical kinetics was included by empirically adjusting the flame spread rate as a function of the Damkohler number [9], [10], and [11]. However, we only have access to the ignition and flame spread data corresponding to the normal ambient environment and may have to contend with composite materials. Our approach is to use [12],

$$
s=V_{f}(t-\tau)
$$

where $s$ is the surface normal distance from the flame front and $V_{f}$ is the quasi-steady flame speed. Equation (11) essentially converts eqs (1) and (2) from a time domain to a surface distance domain. If $\mathrm{V}_{\mathrm{f}}$ is assumed constant during the interval of time integration, then the integrals in eqs (1) and (2) become simpler to integrate as a function of $\mathrm{s}$. In particular, the surface heat flux distribution ahead of the pyrolysis front $\left(\mathrm{at} \mathrm{T}_{\mathrm{s}}=\right.$ $\mathrm{T}_{\mathrm{ig}}$ ) can be conceptualized as shown in Figure 2. This type of heat flux distribution is verified by the experimental data reported in [12], [13], and [14]. Substituting the heat flux distribution into eq (1) and solving for the flame spread rate of the thermally thin material, we obtain an approximation [2] for the flame spread speed,

$$
V_{f}=\frac{\sum_{k} q_{k} s_{k}}{\rho c \delta\left(T_{i g}-T_{e}\right)}
$$

where $\mathrm{q}_{\mathrm{k}}$ and $\mathrm{s}_{\mathrm{k}}$ are directly constructed from the surface heat flux distribution as shown 
in Figure 2. The sum is over distance from the flame surface element $s_{\mathrm{k}}$. Likewise for the thermally thick material we obtain the approximation,

$$
V_{f}=\left(\frac{\sum_{k} q_{k} \sqrt{4 s_{k} / \pi}}{\sqrt{k \rho c}\left(T_{i g}-T_{e}\right)}\right)^{2}
$$

There are many possible further simplifications which lead to well known results. As one example, a correspondence with deRis' results can be obtained by assuming a surface conductive heat flux to be a decreasing exponential function of $s$. Then we convert the summation to an integral and set the ignition temperature to the vaporization temperature. The result for the surface convective heat flux at the flame front is,

$$
q_{f}=\left(\rho_{a} C_{p a} V_{a}\right)\left(T_{f}-T_{i g}\right) / \sqrt{2}
$$

and the exponential decay length (i.e., the thermal length) is,

$$
l_{f}=2 k_{a} /\left(\rho_{a} C_{p a} V_{a}\right) \text {. }
$$

$\mathrm{C}_{\mathrm{pa}}$ is the heat capacity in air under standard atmospheric conditions.

One useful result for thermally thin materials is that the numerator in eq (12) is a constant regardless of the opposed air velocity unless the flame or the ignition temperatures are affected by the air environment or by finite chemical kinetics [9].

Additional components of the surface heat flux distribution at the flame front are the thermal radiative fluxes from the anchored diffusion flame and from other burning regions. These heat fluxes are incorporated into eqs. (12) and (13) for modeling. The thermal radiative heat fluxes from other burning regions can be treated as a constant over the preheated length, $\mathrm{s}_{\mathrm{e}}$. The radiative flux from the adjacent fire plume can be modeled as a decreasing exponential function of $s$. The thermal radiation analysis of the FAST/FSM model was developed to accommodate these heat flux distributions in simulating the flame spread.

Thus any flame spread problem must be examined carefully for two factors. The first is to determine if the material should be treated as thermally thin or thick. This is done by a least-squares fit of the thermally thin and thick analytical solutions to the time to ignition versus irradiance data [6] and selecting the solution giving the best fit. This procedure is not fully automated because some materials are intermediate in their thermal response or are complex composites. Thus the curves must be examined and a judgement rendered as to which is the proper formula to use. The other factor is ascertaining the relative importance of radiative and convective heating of the virgin surface in a flame spread test. One way to separate the relative contribution of each term is to use the 


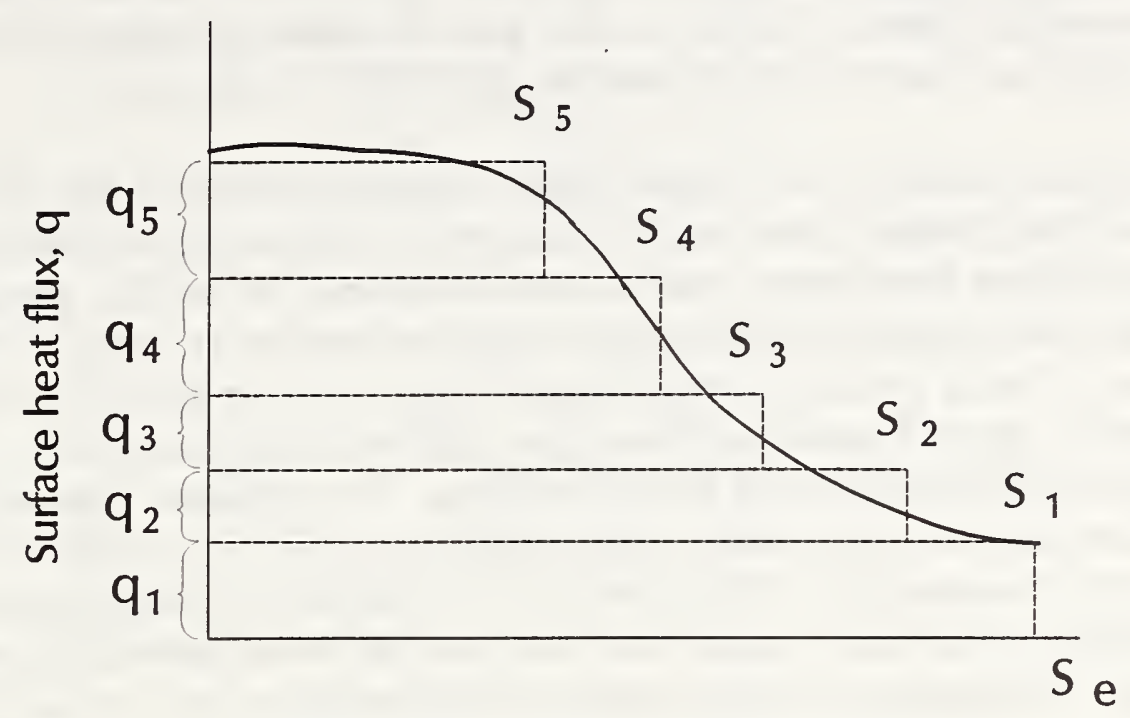

Surface distance from the flame front, $S$

Figure 2. Construction of $q_{k}$ and $s_{k}$ from heat flux distribution fixed ahead of the flame front.

FAST/FSM code itself to calibrate the convective heating contribution to the opposed flow flame spreading on a horizontal (or lateral) panel. This was the approach necessary in the furniture fire model [18] validation with the furniture calorimeter.

The surface heat flux distribution for the upward flame spread in concurrent flow was obtained from the data collected and correlated by Quintiere, Harkleroad, and Hasemi [15]. Their results show that in the continuous flame regions (over the virgin fuel) the total surface heat flux is about $2.5 \mathrm{~W} / \mathrm{cm}^{2}$ (to within $20 \%$ error) for several solid fuels and at flame heights of up to 2.4 meters. At the visible oscillating height of the wall flame (about 2.5 times the continuous flame height), the total surface heat flux has dropped to $0.3 \mathrm{~W} / \mathrm{cm}^{2}$ and is rapidly decreasing with further increases with height. The averaged visible wall height has been correlated by Hasemi [22] and is given in Section 3.5 as eqs (47) and (48). The surface heat-flux distribution is thus modeled as constant up to the solid flame height and then it decreases exponentially with the decay length $70 \%$ of the solid flame height. It's been observed flame radiative flux is dominant ( $80 \%$ of the total) for large wall fires (greater than a $1 / 2$ meter in height). This means a minimum convective heat flux with the value $0.6 \mathrm{~W} / \mathrm{cm}^{2}$. Obviously, at small flame heights the flame radiative flux is small, but the convective heat fluxes increase to 
compensate for it. Under the influence of external irradiance, the total surface heat flux may achieve higher values than $2.5 \mathrm{~W} / \mathrm{cm}^{2}$. Therefore, for purposes of constructing the heat-flux distribution in Figure 2 for upward flame spread, the heat flux at flame front is set to $2.5 \mathrm{~W} / \mathrm{cm}^{2}$, unless the sum of $0.6 \mathrm{~W} / \mathrm{cm}^{2}$ and surface radiative heat flux calculated from the model is larger. Eq (12) is then used for flame spreading on the fabric/foam cushion (thin case) and eq (13) is used for the PMMA (thick case).

A flame spread model requires many surface elements so that the flame spread velocity and the pyrolysis rate can be computed as some accurate function of time. That is, when the flame front passes over a surface element, the surface element begins to burn and its burn history is different than the other surface elements. Thus, when the burning rate of each burning element is added up at a given time, the effect is a total panel burning rate as a function of time that reflects the burning history of each element and which includes the effect of flame spreading. To represent a flame front on the panel surface, there are two approaches. One approach would take a surface element by surface element sequencing. On the basis of a collection of burning surface elements one might be able to construct a flame front and thus the flame spreading direction. The drawback to this approach is the amount of bookkeeping as well as the computer storage required.

The approach which was picked was to represent a burning region as an octagon with its vertices moving outward. This seems to be a practical representation of the flame spread region originating at a piloted ignition point. An elongated eight sided polygon is a practical representation for most flames, including a line ignition source. Each vertex of a polygon is represented by a three-dimensional vector sequenced in a counter-clockwise direction around the polygon normal vector. Thus the direction of the flame spread vector is a normalized cross product of the polygon normal vector with the vector between staggered vertices. The magnitude of the flame spread vector is then the flame spread rate multiplied by the time step, unless it is cut short by intersection with the panel edge. Figure 3 illustrates the geometry used in this calculation. The flame spread on a panel (group of elements) is simulated by the outward movement of the burning polygon. The incremental distance, $\mathrm{s}_{\mathrm{i}}$ (i from 1 to 8 ), of the vertex movement is the flame spread velocity multiplied by the time increment. The flame spread velocity is in turn a function of the preheat temperature, panel orientation, fire plume heating, external irradiance, and properties of ignition and flame spread. The corresponding heating distance, $s_{e, i}$, from a vertex is extrapolated from the midpoint location of the surface element as shown in the figure. The surface heat flux distribution from a vertex outward is discussed later in connection with eq Figure 3 and eq Figure 3.

In concurrent flow flame spread, the flame spreads along the direction of the plume and the flame spread velocity would be relatively high. On the other hand, the flame spreading velocity in opposed flow will usually be low. The flame spread region in either case is by definition the time integration of the flame spread rate in the direction normal to the flame front and along the surface. The polygon approach can easily adapt to a changing flame spread velocity by utilization of three-dimensional vector algebra and 


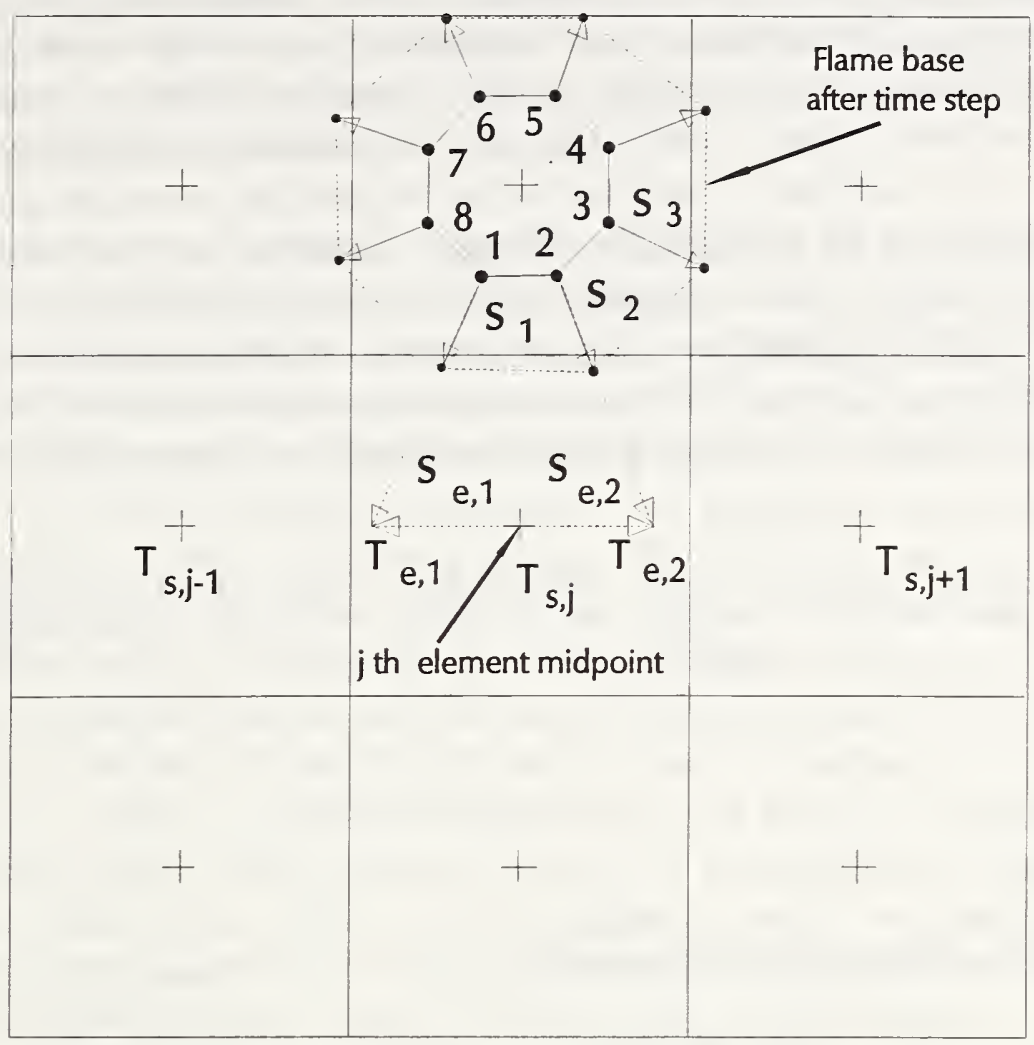

Figure 3. Schematic of simulated flame spread

only needs a few polygon points. For these reasons, the polygon approach was chosen.

In summary, the flame spread procedure used in the flame spread model is illustrated as follows: a cushion panel is divided up into rectangular surface elements. As assumption implicit in the radiation transport is that these elements are almost squarelike. The net surface heat flux and the surface temperature is computed as a function of time at the midpoint of each element. Thermal ignition is assumed to occur when the surface element temperature reaches the ignition temperature. Piloted ignition is assumed to occur when the user selects the time and the location of ignition. Once ignition occurs at a location, a small octagonal burning area is constructed. Flame spreading is simulated by moving the vertices of the burning polygon in a normal outward direction over an incremental distance in an incremental time period.

For the prediction of the flame spread rate, the preheated temperature and the heat flux distribution are the additional parameters needed in eq (12) and (13). As shown in Figure 3, the preheated temperature is taken to be the predicted surface temperature at the virgin surface element midpoint which is the closest to the vertex of a flame spread vector. The surface element midpoint is then extrapolated to the flame spread vector line 


\section{Calculating Flame Spread on Horizontal and Vertical Surfaces}

to define the preheated length, $\mathrm{s}_{\mathrm{e}}$. The external radiative heat flux determined at the surface element midpoint is also extrapolated as a constant heat flux as part of the heat flux distribution. The radiant and the convective heat fluxes between the heated surface and the ambient air are included in the heat flux distribution by treating them as a product of a linearized heat transfer coefficient and the temperature difference between the air and the surface. The increase of external radiative heat flux over the distance $s_{\mathrm{e}}$ to the vertex point at $s=0$ due to the adjacent fire plume is modeled as a decreasing exponential function of s. Lastly, the convective heat flux distribution from the anchored diffusion flame was assumed constant over the distance $1_{\mathrm{f}}$. All these heat flux distributions are substituted into eq (12) or (13) and the summations are converted to integrals. An analytical expression for the flame spread rate can be obtained [6], first for the thermally thin,

$$
T_{i g}-T_{e}=\frac{q_{f} l_{f}+q_{r e} s_{e}+q_{r f} s_{e} \exp \left(-s_{e} / l_{p}\right)}{\rho c \delta V_{f}}+\frac{q_{r f}\left[1-\left(1+s_{e} / l_{p}\right) \exp \left(-s_{e} / l_{p}\right)\right]}{h+\rho c \delta V_{f} / l_{p}}
$$

and then for the thermally thick material,

$$
\begin{aligned}
T_{i g}-T_{e} & =\frac{(2 / \sqrt{\pi})\left[q_{f} \sqrt{l_{f}}+q_{r e} \sqrt{s_{e}}+q_{r f} \sqrt{s_{e}} \exp \left(-s_{e} / l_{p}\right)\right]}{\sqrt{k \rho c V_{f}}} \\
& +\frac{q_{r f}\left[1-\left(1+s_{e} / l_{p}\right) \exp \left(-s_{e} / l_{p}\right)\right]}{h+\sqrt{k \rho c V_{f} / l_{p}}}
\end{aligned}
$$

These two equations can be inverted algebraically to solve explicitly for the flame spread velocity, $\mathrm{V}_{\mathrm{f}}$. Eq Figure 3 was designed to be consistent with the flame spread concepts associated with the LIFT apparatus, although, there is the questionable assumption of treating the convective heat flux from the flame as a constant over the length $1_{\mathrm{f}}$.

\subsection{Scaling of Heat and Mass Release Rates}

The need for scaling the heat and mass release versus scaled time can be ascertained from Figure 4a and Figure 5a, which are plots of the corresponding cone calorimeter data of a typical fabric/foam cushion at three irradiance levels. The fire in general will start at low irradiance levels at ignition and then reach high irradiance levels at the peak burn rate at a later time. There is a real problem in interpolating or extrapolating the data in Figure $4 \mathrm{a}$ and Figure $5 \mathrm{a}$ to the conditions representative of the fire. A detailed model of the fuel pyrolysis and the heat release rate to address this problem is avoided for two reasons. The data shown seem to imply that some complex 
processes are not readily simulated even by the most advanced detailed model. Secondly, the detailed models take up too much computer time, particularly when several surface elements are used in the model geometry. The alternative approach is to develop a self similar solution for use in the flame spread model.

When fuel and oxygen combine, heat is produced (we are concerned only with exothermic reactions) as well as products of combustion. When the reaction goes to completion, that is, only water and carbon dioxide are produced, we refer to this as complete combustion, or stoichiometric combustion. The heat of combustion associated with complete combustion is only a function of the material, and is not a function of the fire environment. In general, though, a reaction is not complete, in that there is excess fuel, carbon monoxide, or other material left over. In this paper, we will refer to a nearly complete combustion as quasi-stoichiometric. This is a useful concept in that it is possible to derive the heat of combustion for nearly complete combustion based on excess pyrolysate, carbon monoxide and so on, that can be measured in a cone calorimeter. Developing variables similar to quasi-stoichiometric heat of combustion and an effective heat of pyrolysis as a function of material burn history are the key concepts for scaling of heat and mass release rates. There are two reasons for calculating the quasistoichiometric heat release flux. First, the burn history is better represented by the accumulated quasi-stoichiometric heat release, particularly when the soot/fuel mass ratio is affected by the actual fire size. Second, when scaling to large flames it is preferable in principle to subtract the actual reduction of heat release due to soot and carbon monoxide formation from the stoichiometric heat release for input to plume models. The processing of the cone calorimeter data is as follows. The measurements of the total heat release flux, fuel mass loss flux, soot mass fraction, and the yield of carbon monoxide as a function of time are used to obtain the quasi-stoichiometric heat release flux as,

$$
\dot{h}_{s t}=\dot{h}_{\text {cone }}+\dot{m}_{\text {fuel }}^{\prime \prime}\left(F_{s, \text { exit }} H_{C}+F_{C O} H_{C O}\right)
$$

Assuming the fraction of the fuel undergoing actual pyrolysis, rather than just changing phase, is the part of the fuel accounting for nearly all of the later combustion, then it is preferable to utilize a parameter more representative of the pyrolysis portion of the fuel than is the fuel mass loss rate parameter. This parameter might be the net surface heat flux required to pyro*lize the fuel because the heat of pyrolysis is usually much higher than the heat of vaporization of water. The net surface heat flux is given by,

$$
q_{s}=q_{c}+q_{r}+q_{o}
$$

where the convective heat flux and the radiative heat fluxes from the flame, the attenuated cone heater, and the burning surfaces are considered. The convective surface heat flux, $q_{c}$, in pool fires was taken from Orloff and deRis [16] and in wall fires

from Ahmad and Faeth [17]. Their formulae are given in Section 3.3. The values 


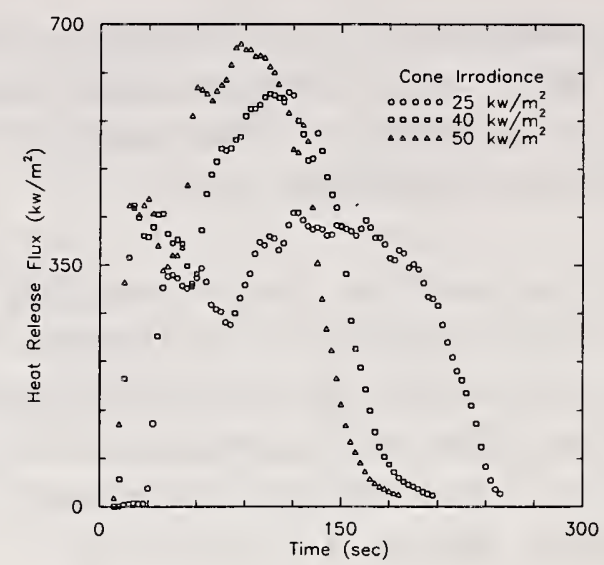

Figure 4a. Original data of heat release flux vs time for LO fabric/FR PU foam.

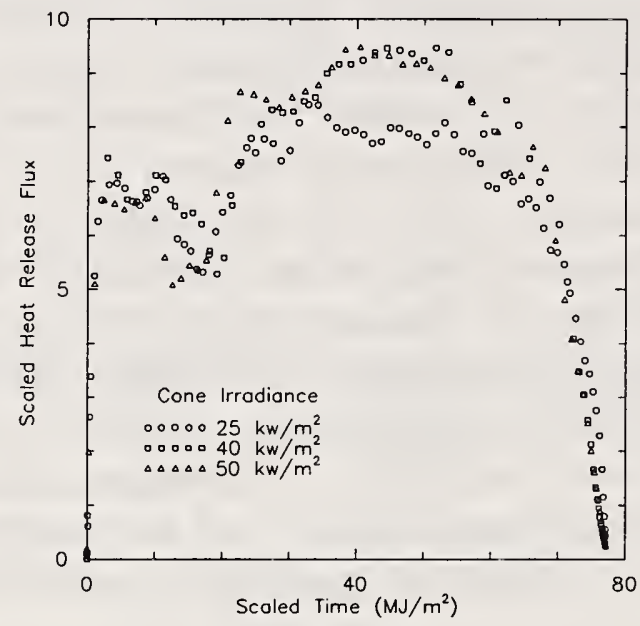

Figure $4 b$. Corresponding scaled heat release fluxfor LO fabric/FR PU foam.

for the radiative heat fluxes in the cone calorimeter are calculated with the mean beam length approximations. In simulating a full-scale fire, the values for the radiative fluxes are assumed available from the current solution of the Hottel's thermal radiation equations, as discussed in section 4 . The scaled heat flux parameter, $\mathrm{q}_{\mathrm{o}}$, accounts for systematic errors in the physical processes. These may include glowing combustion, radiation blocking by stagnant pyrolytic gases, or altered pyrolysis processes at elevated temperatures or irradiances. The heat release flux is scaled to be equivalent to the quasistoichiometric heat of combustion divided by the effective heat of pyrolysis,

$$
q_{s}=\dot{h}_{s t} / h^{*} .
$$

The mass release flux (pyrolysis rate per unit area) is scaled to be equivalent to the inverse of the effective heat of pyrolysis, 


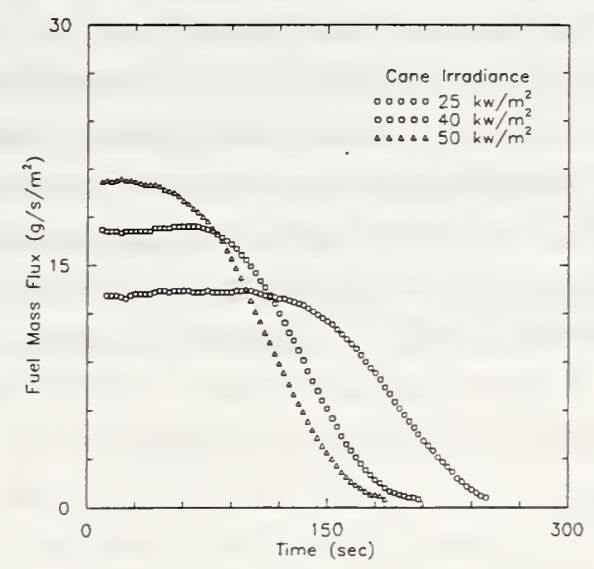

Figure 5a. Original data of fuel release flux vs time for LO fabric/FR PU foam.

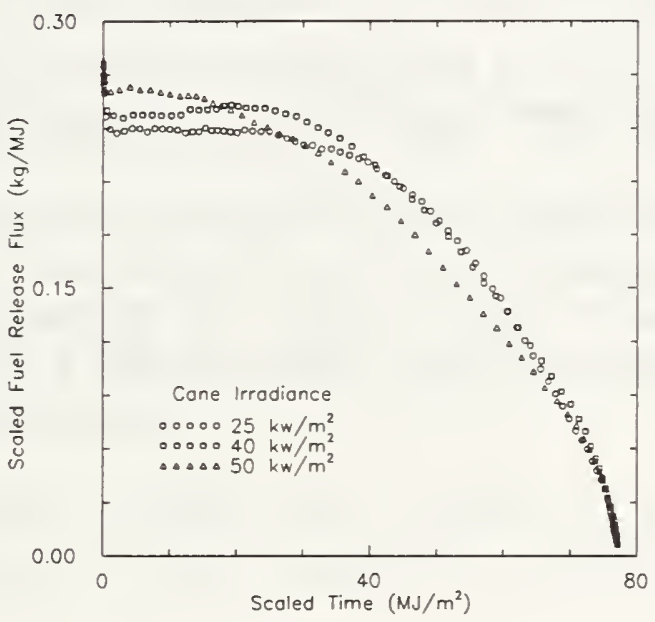

Figure 5b Corresponding scaled fuel release flux versus scaled timefor LO fabric/FR PU foam material

$$
m^{*}=\dot{m}^{\prime \prime} / h^{*} \text {. }
$$

The underlying basis for scaling the physical parameters comes from the observation made earlier, that the Laplace transform of the integral expressions for temperature and other variables can be solved exactly and then, with some approximations in the parameters, inverted to provide a solution for these variables. A similar observation can be made about the experimental data. If one writes an integral experession for the time and heat release as a function of time, performs a Laplace transform on the expression as well as the experimental data, one observes that all the exprsssion (in transform space) describes the experimental data reasonably well, if the scaling function is chosen appropriately and that this function has only two parameters, 
here called "d" and "e." This function is equivalent to coefficients of a polynomial in normal least squares fitting procedures, although not the same function. Based on these observations, we can write down an analytic expression for the scaled time and heat release rate. By chosing the coefficients of the transformed data properly, we can collapse the experimental data to a set of self-similar solutions. The fit is certainly not perfect, as will be seen, but within the accuracy of the proposed flame spread model and the experimental data which is being used, it is entirely adequate. Once again, in terms of improved accuracy, the coefficients ( $d$ and $e$ in the following equations) are better representations of the physical world if there are a large number of flux measurements (heat release vs time for a given imposed flux). With this in mind, we find that the scaled time (the burn history) was best represented by an effective heat release per area as,

$$
T^{*}=\int_{o}^{t} \dot{h}_{s t}(1+G) d t
$$

where

$$
\begin{gathered}
G=0 \quad \text { for } \int_{o}^{t} \dot{h}_{s t} d t \leq e Q^{\prime \prime}{ }_{r e f} d /(1+d) \\
o r \quad \geq Q^{\prime \prime}{ }_{e}-e Q^{\prime \prime}{ }_{r e f} /(1+d) \\
G=\left(Q^{\prime \prime}{ }_{r e f}-Q^{\prime \prime}{ }_{e}\right) /\left(Q^{\prime \prime}{ }_{e}-e Q^{\prime \prime}{ }_{r e f}\right) \\
Q^{\prime \prime}{ }_{e}=\int_{o}^{t_{\text {end }}} \dot{h}_{s t} d t
\end{gathered}
$$

and

$$
Q_{\text {ref }}^{\prime \prime}=T^{*} \quad \text { at } \quad t=t_{\text {end }}
$$

The time stretching parameter, G, ensures that the scaled burnout time is similar for the similar materials. $G$ is given by eq (25) within the domain shown in eqs (23)(24). Outside of this domain, $G$ vanishes. These similar materials will have nearly the same burning behavior at the beginning and the ending part of their burn history. Thus the middle part of a material's burning history will be only affected by the time stretching parameter as controlled by the scaling parameters e and $d$ [18]. The reference burn 
history, specified by $Q_{\text {ref }}$ at $t_{\text {ref }}$. The sample is assumed to be "burned out" at $t_{\text {end }}$. Setting $\mathrm{e}=0.5$ will cause half the total burn history to be affected by the time stretching and setting $d=1$ will put the affected region directly in the middle of the total burn history. Other values of $\mathrm{d}$ and e can be tailored to represent composite matierals. The objective of calibrating the scaling constants is to make the plots of $\dot{q}^{*}$ or $\dot{m}^{*}$ versus $t^{*}$ for different cone heater radiances collapse to a single curve. In principle this could be done with serveral data sets and a minimization program. In practice it is easier to use three or four curves and to inspect the results visually. This was the technique used to achieve the fits shown in figures 4 and 5 .

The cone calorimeter data of heat and mass release versus time for a typical fabric/foam cushion at three irradiance levels are shown in Figure 4a and Figure 5a. The corresponding scaled heat and mass release fluxes versus the scaled time as a result of using the scaling eqs (18)-(22) are shown in Figure $4 \mathrm{~b}$ and Figure $5 \mathrm{~b}$. These figures demonstrate the approximate collapse of the data into a single curve after calibrating the three scaling constants. This scaling procedure was found to work also for wood and PMMA materials. Thus the data in Figure $4 \mathrm{~b}$ and Figure $5 \mathrm{~b}$ permit arbitrary variations in the net surface heat flux and in the burning history in order to calculate the heat and mass release flux of the surface elements in the flame spread model.

The prediction of the local burn history in this model can be explained by using eqs (18) to (27) as follows. The integral in eq (22) is evaluated with a trapezoidal numerical integration to produce the scaled data in Figure $4 \mathrm{~b}$ and Figure $5 \mathrm{~b}$. Substituting the scaled heat release flux as a function of the scaled burn history from eq (20) into eq (21) and rearranging we end up with

$$
\int_{t_{i}}^{t_{i+1}} q_{S}(t) d t=\int_{T^{*}{ }_{i}}^{T^{*}{ }_{i+1}} d T^{*} /\left[\dot{h}^{*}\left(T^{*}\right)\left(1+G\left(T^{*}\right)\right)\right] .
$$

The right hand side term of this equation utilizes data presented in Figure $4 \mathrm{~b}$ and the left hand side term uses the net surface heat flux given by eq (19) as a function of time. Thus eq (28) provides a relationship between the real burn time, $\mathrm{t}_{\mathrm{i}}$, and the scaled burn time, $\mathrm{T}_{\mathrm{i}}^{*}$. Using a trapezoidal numerical integration of the right hand side of eq Figure 5 and an Euler numerical integration of the left hand side, it is simple to keep the local burn history in step with the local real burn time.

The receding depth of the burning material is assumed approximately proportional to the scaled burn time. The constant of proportionality is the thickness of the original material divided by the ending scaled burn time. If all the surface elements in a panel are burning, then the flame spread polygon is receded to keep in a planar contact with the burning surface elements. When the flame spread polygon is finally shifted by an amount equal to the material thickness, the panel no longer supports pyrolysis and combustion. 


\subsection{Local Convective Heat Flux and Fuel Pyrolysis Rate}

The local convective heat flux and the fuel mass loss rate given in eq (19) and (21) can be evaluated as follows. The formulae for the convective surface heat transfer in pool fires was taken from Orloff and deRis [16] and in a wall fire from Ahmad and Faeth [17]. Starting with the pool fires, the convective heat transfer is,

$$
q_{c, p o o l}=h_{p}\left(T_{f}-T_{\infty}\right)\left(\frac{y}{\exp (y)-1}\right)
$$

where

$$
y=\dot{m}^{\prime \prime} c_{p a} / h_{p}
$$

and

$$
\dot{m}^{\prime \prime}=\left(q_{c}+q_{r}+q_{o}\right) / H_{f}
$$

$h_{p}$ is the effective heat transfer coefficient in a pool fire, given as $0.008 \mathrm{~kW} / \mathrm{m}^{2}[16] ; T_{f}$ is the flame temperature, taken to be $1250 \mathrm{~K}$ for now; $\mathrm{C}_{\mathrm{pa}}$ is the heat capacity of air; and $\mathrm{H}_{\mathrm{f}}$ is the effective heat of pyrolysis as a function of burn history. Substituting the convective heat flux from eq (29) into eq (31) yields,

$$
h_{p}\left(T_{f}-T_{\infty}\right)\left(\frac{y}{\exp (y)-1}\right)+q_{r}+q_{o}-\left(h_{p} H_{f} y / c_{p a}\right)=0
$$

Using the slope intercept method to solve eq (32) leads to a value for y. Substituting the solution for y into eq Figure 5 yields a value for the fuel mass flux. Then eq (29) is used to obtain the convective heat flux in the pool fire.

The convective heat transfer for a wall fire [17] is obtained as

$$
q_{c, \text { wall }}=\dot{m}^{\prime \prime} L_{f}
$$

where

$$
\begin{gathered}
\dot{m}^{\prime \prime}=\max \left(\dot{m}_{t}^{\prime \prime}, \dot{m}_{l}^{\prime \prime}\right) \\
\dot{m}_{l}^{\prime \prime}=0.495\left(\frac{\mu_{\infty}}{x}\right)\left(\frac{\beta}{1+\beta}\right)\left(\frac{(1+\beta) \ln (1+\beta)}{P_{r} \beta}\right)^{\frac{1}{2}}\left(\frac{3(\beta+\tau) \eta_{f}+\tau}{1+P_{r} / 2(1+\beta)} G r_{x}\right)^{\frac{1}{4}}
\end{gathered}
$$




$$
\dot{m}_{t}^{\prime \prime}=0.0516\left(\frac{\mu_{\infty}}{x}\right)\left(\frac{\beta}{1+\beta}\right)\left(\frac{(1+\beta) \ln (1+\beta)}{\beta / \xi}\right)^{\frac{4}{5}}\left(\frac{3(\beta+\tau) \eta_{f}+\tau}{1+1 / 2 \xi(1+\beta)} G r_{x}\right)^{\frac{2}{5}}
$$

and

$$
\begin{aligned}
& \beta=\mathrm{c}_{\mathrm{pf}}\left(\mathrm{T}_{\mathrm{f}}-\mathrm{T}_{\mathrm{b}}\right) / \mathrm{L}_{\mathrm{f}} \\
& \tau=\mathrm{c}_{\mathrm{pa}}\left(\mathrm{T}_{\mathrm{b}}-\mathrm{T}_{\infty}\right) / \mathrm{L}_{\mathrm{f}} \\
& \eta_{\mathrm{f}}=1-\left[(1+1 / \beta) /\left(1+1 / \mathrm{r}_{\mathrm{f}}\right)\right]^{1 / 3} \\
& \mathrm{r}_{\mathrm{f}}=0.19, \text { and } \xi=0.5^{4}
\end{aligned}
$$

The local Grashof number at an inclined angle, $\phi$, is

$$
\mathrm{Gr}_{\mathrm{x}}=\mathrm{L}_{\mathrm{f}} \mathrm{g} \mathrm{x^{3 }} \cos (\phi) /\left(4 \mathrm{c}_{\mathrm{pa}} \mathrm{T}_{\infty} \nu_{\infty}^{2}\right)
$$

Using eq Figure 5 and Figure 5, we obtain an expression for $\mathrm{L}_{\mathrm{f}}$ as,

$$
\left(H_{f}-L_{f}\right)-\left(q_{r}+q_{o}\right) / \dot{m}^{\prime \prime}=0
$$

Since eqs (32) to (38) provides $\dot{m}^{\prime \prime}$ as a direct function of $\mathrm{L}_{\mathrm{f}}$, the slope intercept method solves eq Figure 5 for the values of $L_{\mathrm{f}}$. This value of $\mathrm{L}_{\mathrm{f}}$ is substituted into eq Figure 5 to obtain a value for the convective heat flux for the wall fire. The determination of the convective heat flux over burning surfaces at different orientations is important during the early phase of the fire growth, because convective heat from the flames then is a major factor in fuel pyrolysis.

\subsection{Scaling of Combustion Products and Soot}

A functional relationship between the soot extinction coefficient and the flaming soot absorption coefficient, which is critical in calculating the thermal radiation field, was developed for application to the flame spread model. Basic data from an early version of the cone calorimeter were used to derive accurate values for the heat and mass release fluxes, oxygen consumption rates, product ratio of $\mathrm{CO}$ to $\mathrm{CO}_{2}$, and the soot extinction area data. The soot extinction data were available only in certain forms, such as the averaged value or the peak value. Other combustion products were estimated assuming stoichiometric conditions within the fire, as the water vapor for example. With these available data the only two additional data plots of significance are $\mathrm{CO} / \mathrm{CO}_{2}$ ratios and soot extinction areas versus time as shown in Figure 6a and Figure 7a, respectively.

${ }^{4}$ The values are obtained from ref 17 , and are for materials which do not readily conduct. It turns out to be rather insensitive for all materials which have been tested in the veritcal (wall) configuration. 
The combustion products, excluding the soot, in the current model are scaled the same way as the mass release flux. It is therefore assumed that eq (20), (21), and those for the combustion products are only a function of the burn history and of the oxygen concentration in the air. The soot formation is known to be affected by the thermal radiation field and the fire plume shape, and thus needed a separate scaling formulation. Consequently, a theoretical relationship between the specific soot extinction area and the flaming soot absorption coefficient was developed after a critical review of McCaffrey's and of Bard and Pagni's work [19], [20]. The scaling for soot production is different in the sense that it is also affected by the size of the flame and by the heat of combustion for the fire. This is given by

$$
\begin{gathered}
F_{s}=\sigma_{p}^{e} / \sigma_{s}^{e} \\
\sigma_{p, \text { exit }}^{e}=C\left(T_{f}, T_{\infty}\right) k_{s, \text { flame }}\left(\dot{Q} / \dot{M}_{f u e l}\right)
\end{gathered}
$$

and

$$
k_{s, \text { flame }} L=\left\{\begin{array}{ccc}
\left(1.5 k_{s, \max } L\right)^{3 / 2} & \text { for } & k_{s, \text { flame }} L<0.3 \\
\left(k_{s, \max } L\right) & \text { for } & k_{s, \text { flame }} L \geq 0.3
\end{array}\right\}
$$

The specific soot extinction area, $\sigma_{\mathrm{s}}^{\mathrm{e}}$, and the maximum soot absorption coefficient, $\mathrm{k}_{\mathrm{s}, \max }$, are treated as constants for the present version of the model [31] although they are generally functions of the material burn history and oxygen concentration. Eq (44) is equivalent to Bard and Pagni's expression [20] for the flaming soot absorption coefficient. Given a value of $k_{s, \max }$, eq (44) is used to calculate the soot absorption coefficient, $\mathrm{k}_{\mathrm{s}, \text { flame }}$, for a given scale of fire and a point in the burn history. Using this value of $\mathrm{k}_{\mathrm{s} \text {,flame }}$, the exiting soot extinction area is calculated by eq (43). Finally, eq (42) provides the soot mass fraction for the measured value of the specific soot extinction area and is plotted in Figure 7a. The scaled soot mass flux, which is the product of eq (42) and (21), is plotted versus the material scaled burn time in Figure 7b.

\subsection{Heat and Mass Release Rates of Flame}

In the flame spread model, two basic flame shapes are considered. The first is the parallelepiped flame shape with the horizontal flame spread polygon. The other is the wedge-like shape defined by Ahmad and Faeth boundary layer model for the wall fire [17]. The thicknesses of a wall flame for laminar and turbulent flow are respectively given by, 


$$
\delta_{l}=4.2814 x\left[\frac{(1+\beta) \ln (1+\beta)}{P_{r} \beta}\right]^{\frac{1}{2}}\left[\frac{3(\beta+\tau) \eta_{f}+\tau}{1+P_{r} / 2(1+\beta)} G r_{x}\right]^{-\frac{1}{4}}
$$

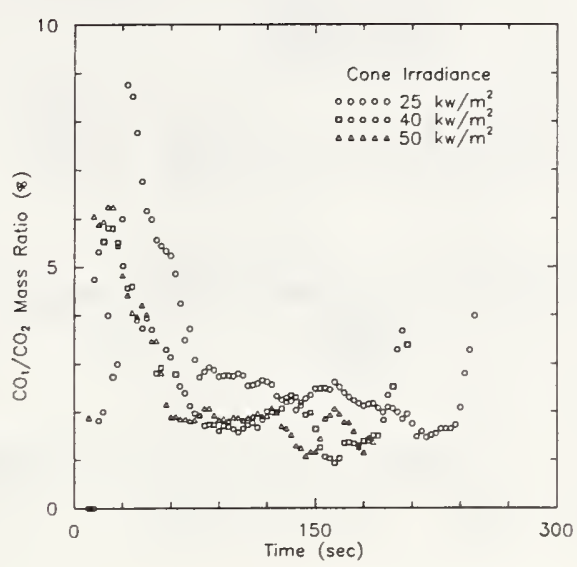

Figure 6a. Processed data of $\mathrm{CO}$ and $\mathrm{CO}_{2}$ mass ratio for $\mathrm{LO}$ fabric/FR PU foam.

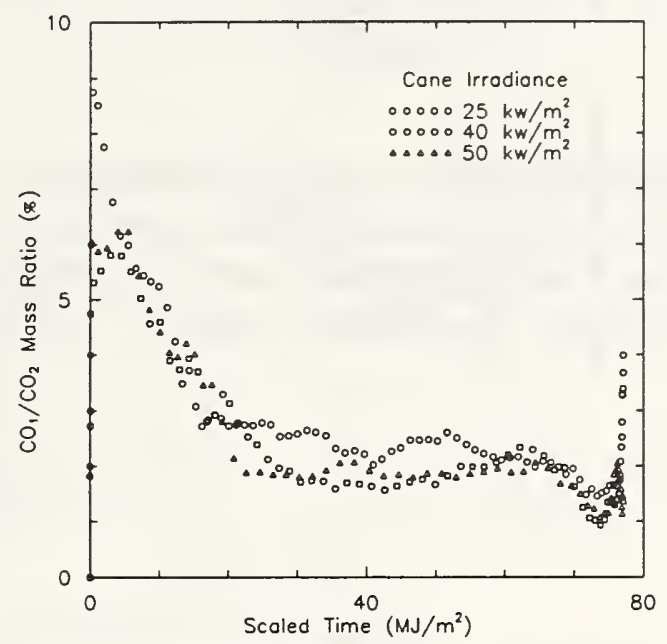

Figure $6 \mathrm{~b}$ Processed data of $\mathrm{CO}$ and $\mathrm{CO}_{2}$ mass ratio versus scaled time for $\mathrm{LO}$ fabric/FR PU foam 


$$
\delta_{t}=0.199571 \times\left[\frac{(1+\beta) \ln (1+\beta)}{\beta / \xi}\right]^{\frac{4}{5}}\left[\frac{3(\beta+\tau) \eta_{f}+\tau}{1+1 / 2 \xi(1+\beta)} G r_{x}\right]^{-\frac{1}{10}}
$$

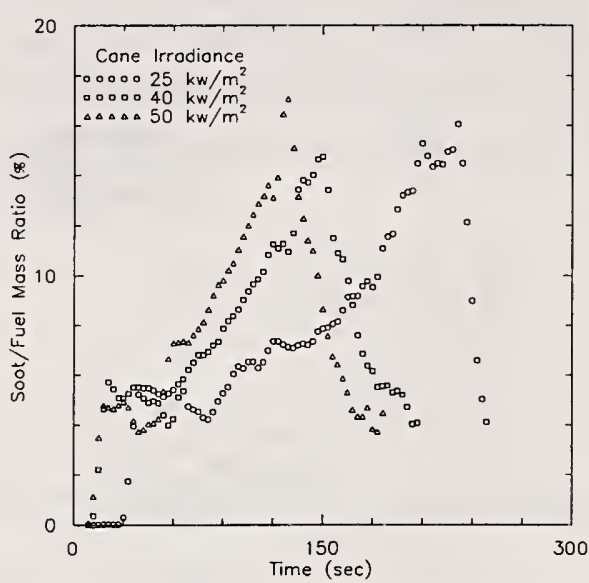

Figure 7a. Calculated soot to fuel mass ratio vs time for LO fabric/FR PU foam.

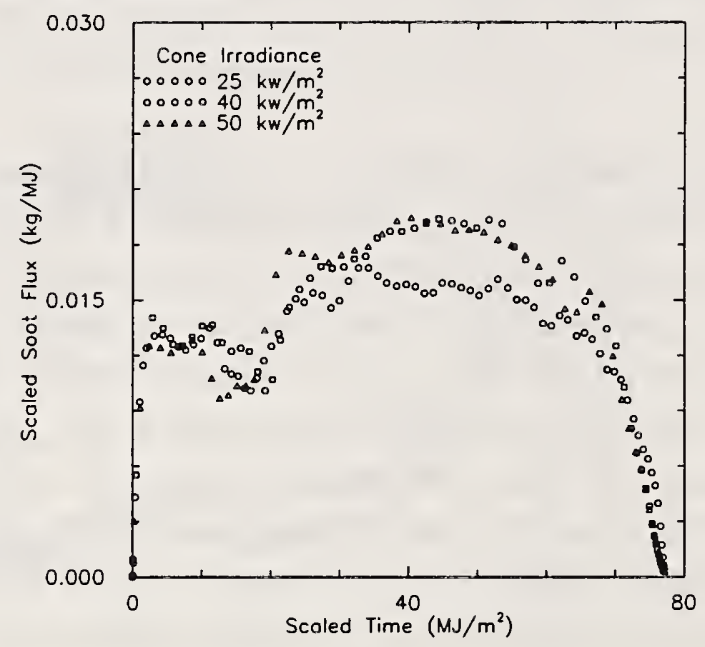

Figure $7 \mathrm{~b}$ Calculated scaled soot mass flux versus scaled time for LO fabric/FR PU foaml

As a consequence, the solid flame height as an additional parameter is needed to define the overall flame shape. Cetegen, et. al. [21], formula for averaged visible pool fire height (which is 2.5 times the solid flame height) is, 


$$
Z_{f_{p}} / D=\left\{\begin{array}{ll}
3.3\left(\dot{Q}_{D}^{*}\right)^{\frac{2}{3}} ; & \dot{Q}_{D}^{*}<1 \\
3.3\left(\dot{Q}_{D}^{*}\right)^{\frac{2}{5}} ; & \dot{Q}_{D}^{*}>1
\end{array}\right\}
$$

where

$$
\dot{Q}_{D}^{*}=\dot{Q}_{C} /\left[\rho_{a} C_{p} T_{\infty} g^{\frac{1}{2}} D^{\frac{5}{2}}\right]
$$

Hasemi's formula [22] for averaged visible wall fire height is,

$$
Z_{f_{w}} / Z_{w}=\left\{\begin{array}{ll}
6.0\left(\dot{Q}_{w}^{*}\right)^{\frac{4}{5}} ; & \dot{Q}_{w}^{*}<1 \\
6.0\left(\dot{Q}_{w}^{*}\right)^{\frac{2}{3}} ; & \dot{Q}_{w}^{*}>1
\end{array}\right\}
$$

where

$$
\dot{Q}_{w}^{*}=\dot{Q}_{C} /\left[\rho_{a} C_{p} T_{\infty} g^{\frac{1}{2}} Z_{w}^{\frac{3}{2}} Y_{w}\right]
$$

Both flame shapes have surface elements with their positions, areas and normal vectors defined so that view factors for the thermal radiation model can be numerically calculated among the flames and the panel surfaces. Once a set of burning surface elements are assigned to a flame, the fuel mass release rate into the flame can be calculated by a summation,

$$
\dot{M}_{\text {fuel }}=\sum_{i}\left(q_{c}+q_{r}+q_{o}\right)_{i} \dot{m}_{i}^{*}\left(T_{i}^{*}\right) A_{i}
$$

and the combustion products mass rate is given by,

$$
\dot{M}_{j}=\sum_{i}\left(q_{c}+q_{r}+q_{o}\right)_{i} \dot{m}_{i}^{*}\left(T_{i}^{*}\right) F_{j}\left(T_{i}^{*}\right) A_{i}
$$

The heat release flux from a surface element is calculated as the quasistoichiometric heat release flux minus the heat release flux of the incomplete combustion products of soot and carbon monoxide. The heat release rate of the flame is then the summation of the heat release rates from all incremental areas of the burning surface elements. Considering the incomplete combustion due to the production of soot and 
carbon monoxide, the heat release rate for the flame can be given as,

$$
\dot{Q}=\sum_{i}\left(q_{c}+q_{r}+q_{o}\right)_{i}\left[\dot{h}^{*}-\dot{m}^{*}\left(F_{s} H_{c}+F_{c o} H_{c o}\right)\right]_{i, T_{i}} \cdot A_{i}
$$

where $\mathrm{F}_{\mathrm{co}}$ is the mass fraction of carbon monoxide as a function of the scaled burn time of the surface element. Eq (53) shows the contribution of each of the predicted physical processes to the heat release rate of the flame. The virgin surface heating and the flame spread ultimately determines the number of burning surface elements as a function of time and the corresponding structure of the overall thermal radiation field (see the discussion in the next section). The scaled burn times of the surface elements directly determine the scaled heat and mass release fluxes and the carbon monoxide mass fractions. Also, eq (53) demonstrates that the accelerative growth of the flame heat release rate is due to two main competing factors: the rate of increase of number of burning surface elements and the rate of increase of the surface radiative heat flux. Eventually, a peak value of the flame heat release rate is reached and then its rate of decrease is controlled by the burnouts of the surface elements. 


\section{THERMAL RADIATION ANALYSIS}

In large fires, thermal radiation dominates nearly all physical processes. Since only a few gas zones and not very many surface elements are considered, Hottel's zonal model was chosen for the thermal radiation analysis. Applying the mean beam length approximations to the key components of Hottel's zonal model, the evaluation of the complex exchange areas between the flame and the surfaces was simplified to only involve calculations of the configuration factors, surface areas, and emissivities. Also, taking advantage of energy conservation requirements resulted in an efficient scheme of solving the thermal radiation equations.

\subsection{Hottel's Zonal Thermal Radiation Analysis}

Hottel's zonal model [23] is the simplest radiation model that takes into account different gas volume radiation sources and values of surface emissivities less than unity. The method for an enclosure with isothermal, optically thin, and elemental gas volumes was extended to isothermal, moderately thick (optically), and finite gas volumes by considering the fact that energy is conserved, and that at each instance of time the gas volume as well as the surfaces are in thermal equilibrium. We apply the Kirchoff relation which says that the energy in equals the energy out for each element or volume that we consider. Under the thermal equilibrium condition and with the Kirchoff's relation for diffuse emission, we have $\dot{\mathrm{Q}}_{\mathrm{i}}=\dot{\mathrm{Q}}_{\gamma}=0$. The $\dot{\mathrm{Q}}$ 's are the net heat fluxes to a surface element or volume element of the gas.

\subsection{Volume Emissivities Due to Soot, $\mathrm{H}_{2} \mathrm{O}$, and $\mathrm{CO}_{2}$}

The effective absorption coefficient, $\mathrm{a}_{\gamma}$, is the absorption coefficient in the optically thin limit, i.e., when $\mathrm{V}$ is small. To account for a finite volume size, the mean beam length approximation of Orloff and deRis [16] can be extended to,

$$
4 a V=A_{b} \epsilon_{T}
$$

and

$$
L=3.6 V / A_{b}
$$

where "a" is the absorption coefficient $\left(\mathrm{m}^{-1}\right), \mathrm{V}$ is the gas volume, $\varepsilon$ is the total gas emissivity and $A_{b}$ is the area of the bounding box for the volume $V$. This is an approximation which is in keeping with the zone model approach. Certainly, if a more detailed analysis were required, then the gas volume would need to be partitioned similar to what is required for a computational fluid mechanics calculation. The total volume 
emissivity, $\epsilon_{\mathbf{T}}$, can be calculated as follows:

$$
\epsilon_{T}=\epsilon_{s}+\epsilon_{g}\left(1-\epsilon_{s}\right)
$$

where

$$
\begin{gathered}
\epsilon_{s}=1-\exp \left(-k_{s} L\right) \\
\epsilon_{g}=\epsilon_{C O 2}+\epsilon_{H 2 O}-\epsilon_{D} \\
\epsilon_{C O 2}=0.20\left[1-\exp \left(-2.47 \sqrt{P_{C O 2} L}\right)\right] \\
\epsilon_{H 2 O}=0.673[1-\exp (-1.21 \sqrt{X})] \\
\epsilon_{D}=F\left(T_{g}\right) G(\zeta)\left[\log \left(101.3\left(P_{C O 2}+P_{H 2 O}\right) L\right)\right]^{2.76} \\
F\left(T_{g}\right)=-1.0204\left(10^{-6}\right) T_{g}^{2}+2.2449\left(10^{-3}\right) T_{g}-0.23469 \\
G(\zeta)=\zeta /(10.7+101 \zeta)-\zeta^{10.4} / 111.7
\end{gathered}
$$

and

$$
\zeta=P_{\mathrm{H} 2 \mathrm{O}} /\left(P_{\mathrm{H} 2 \mathrm{O}}+P_{\mathrm{CO} 2}\right)
$$

This is called the mean beam length approximation and is a simple, straightforward way to calculate an absorption length which is in keeping with the spirit of the zone model approach.

The partial gas pressure within the moving fire plume is approximated as,

$$
P_{g}=\dot{M}_{g} R_{g} T_{f} / \dot{V}_{p}
$$

where $\dot{V}_{p}$ is the volume flow of the plume via the McCaffrey formula [19]. The plume gases have contributions from both the combustion and from the entrained air. The partial gas pressures for the upper and lower gas layer are obtained using the idea gas 
law for simple gases.

\subsection{Evaluation of Hottel's Exchange Areas}

There are three heat transfer calculations which are included in such an analysis: surface-gas, surface-surface and gas layer to gas layer. Of the three, the surface-gas exchange area is the most important in the radiation equations because it dominates the net heat transfer as a result of large temperature difference occurring between a flame and a surface. From Hottel and Sarofim [24], and using the mean beam length concept, formulas for all the Hottel's exchange areas can be simplified to involve only configuration factor, surface areas, and emissivities of both the flame and body surfaces. Therefore, the approximations to $s_{i} g_{\gamma}, s_{i} s_{j}$, and $g_{\gamma} g_{\mu}$, the surface-gas, surface-surface and gas layer to gas layer respectively, are

$$
\begin{gathered}
\frac{\left(s_{i} g_{\gamma}\right)}{A_{i}}=\tau\left(S_{i \gamma}-L_{\gamma}\right) \cdot \epsilon_{T_{i, \gamma}} \cdot F_{i, \gamma} \\
s_{i} s_{j}=\tau\left(L_{\gamma}\right) A_{i} F_{i, j} \\
g_{\gamma} g_{\mu}=\tau\left[S_{\gamma, \mu}-\left(L_{\gamma}+L_{\mu}\right)\right] \epsilon\left(L_{\gamma}\right) \in\left(L_{\mu}\right) A_{\gamma} F_{\gamma, \mu}
\end{gathered}
$$

where

$$
L=0.95 V_{\gamma} / A_{P_{i, \gamma}}
$$

and

$$
F_{i, \gamma}=\frac{\cos \left(\theta_{i, \gamma}\right)}{\pi}\left(\frac{A_{P_{i, \gamma}}^{*}}{l_{i, \gamma}^{2}}\right)
$$

The configuration factor, $\mathrm{F}_{\mathrm{i}, \gamma}$, is directly calculated analytically for a specified flame geometry or computationally for a generalized flame shape. Eq (71) is then used to calculate an effective projected area, $A_{p}^{*}$, which is used in place of $A_{p}$ in eq (70). One can work backwards, then to obtain $\epsilon_{\mathrm{T}}$ from eq (56). Finally, eq (67) is used to obtain the exchange area $s_{i} g_{\gamma}$ for any distance from the flame volume or for any optical thickness. Also, eq (67) reduces to Orloff's expression [25] for moderate optical thickness when the surface element is far from the flame volume. For a surface element located on the flame bounding surface, eq (55) is equal to eq (70), which results in $A_{p}=$ (0.95 $\left.\mathrm{A}_{\mathrm{b \gamma}} / 3.6\right)$.

To achieve greater accuracy in the vicinity of the flame base region, $l_{\mathrm{i}, \gamma}$ and $\theta_{\mathrm{i}, \gamma}$ have been modified to correlate with advanced thermal radiation calculations for regions 
around a conical frustrum, [25], [26] and [27]. The result is,

$$
\begin{gathered}
l_{i, \gamma}=r_{i, \gamma}+r_{\gamma} \\
\pi r_{\gamma}^{2}=\left(0.95 A_{\gamma} / 3.6\right)[0.5874+0.0613 \exp (L / r)] \\
\min \theta_{i, \gamma}=\cos ^{-1}\left(\cos ^{2}(\alpha / 2)\right)
\end{gathered}
$$

Simplifying all the Hottel's exchange areas has made possible a practical thermal radiation model of finite, three-dimensional gray flames and bodies. The information required for the thermal radiation analysis are the flame and body structures and properties and the output is the net thermal radiative powers of all gas layers, flames, and surface elements. 


\section{GEOMETRY CONSTRUCTION AND INPUT DATA}

The implementation of the thermal ignition and flame spread in the flame spread model, FSM, is based on the geometries chosen for the model. A three-dimensional vector analysis is used to describe the geometries for the objects, flame spreading regions, flame shapes, and room. A panel with square surface elements is used to simulate burning of combustible wall elements at any orientation or a horizontal slab in a room. The panel is a quadrilateral plane which can have any position or orientation in a three-dimensional space. The panel can have several burning surface elements, each having its own fuel loss and heat release rates as a function of burn history, and the panel can also have a few burning polygons which represent the flame spreading process. The corner points of the panel are defined in a counter clockwise direction around the normal vector of the panel using inputs of panel's length and angle specifications. Each surface element on the panel, flame, or room is characterized by its three-dimensional midpoint position vector, the element normal vector, and the element actual area. Also, dividing the panel into surface elements yields the surface temperature distribution that is used to calculate the flame spread. Sometimes, a surface element will spontaneously ignite if preheated sufficiently. This will lead to a new flame spread polygon. This process in turn defines when a surface element is ignited and when it is burning. The panel's geometry, location, and orientation in the room are specified within the room. Also, piloted ignition is assumed to occur when the time and the location of ignition on the panel surface is set. Management of input database files to the flame spread model requires separate input database files to the flame spread model and modification to the FAST database file. One of the input files provides definition of the panel shape, position, and orientation; another file provides the complete cone calorimeter database for different materials; another provides input data for thermal ignition and flame spread.

\subsection{Modification to FAST Database File}

Basic modifications to normal input file are the additions to the fire specification. The discussions which follow are based on a preliminary implementation in the CFAST model [28]. Thus there are references to parameters and terms which are defined for this particular model. The FSM is more general and can be used with other models. However, its function depends on the environment, so a particular implementation of a fire model was necessary to demonstrate the effect of flame spread on the predicted environment.

A panel fire is specified by setting the fire type parameter to 3 (LFBT=3) in the data file. Once the panel fire source is specified, the user provides the following information:

LFBT fire type parameter to indicate the type of fire,
1 unconstrained fire
$2,3, \ldots$ constrained fire (set to 3 for the flame spread model)

FTIME for the flame spread model, this parameter is redefined to be the synchronized time step of 
both the flame spread model, FSM and FAST

BENCH the label BENCH indicates the name of the bench scale thermal, ignition, and flame spread properties database file, FRPUHO.DAT, to be used with the flame spread model

PANEL the label PANEL indicates the name of the panel geometry, orientation, and location file, PANEL.DAT

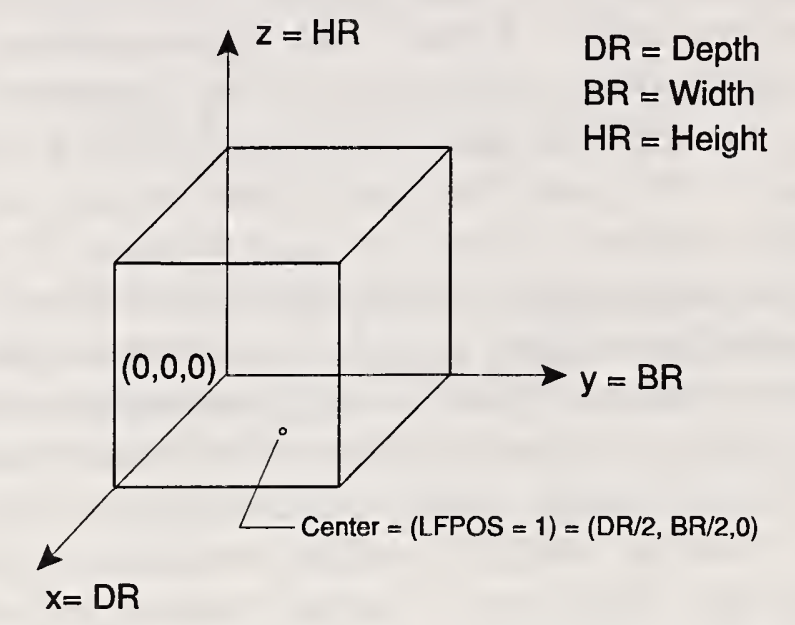

Figure 8 Geometry of the room of fire origin and the global xyz-coordinates.

CONEF the label CONEF indicates the name of the cone calorimeter database file at a single cone irradiance level and for the same material as referred to by BENCH and PANEL, CHOLCA.DAT

The geometry of the room of fire origin is specified in terms of Room Depth (DR), Room Width (BR), and Room Height (HR). The relation of the room geometry (DR, $\mathrm{BR}$, and HR) and the global xyz-coordinates is shown in Figure 8. In this figure, DR, $\mathrm{BR}$, and $\mathrm{HR}$ are along $\mathrm{x}, \mathrm{y}, \mathrm{z}$ axes respectively. Figure 9 shows the initial position of a panel at different fire positions (LFPOS $=1,2$, and 3 ) in the room of fire origin. In each fire scenario, the initial coordinates of corner 1 of the panel are the same as that one of the fire position, LFPOS.

\subsection{Panel Database File}

The input data required by the flame spread model to define geometry, orientation and location of the burning panel in the room of fire origin, and the ignition location on the panel is the user supplied Panel Database File. The flame spread model reads the data in free format and in the sequential order for the variables defined below.

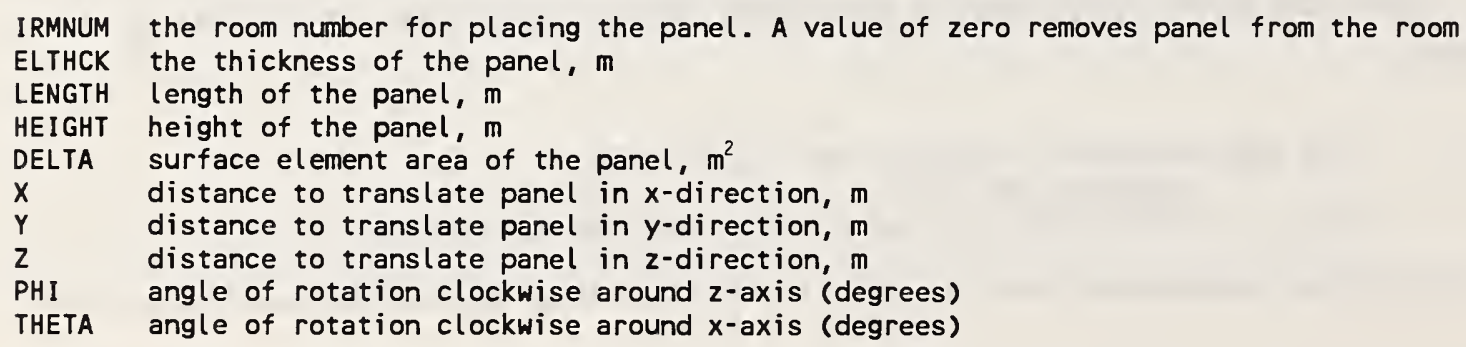




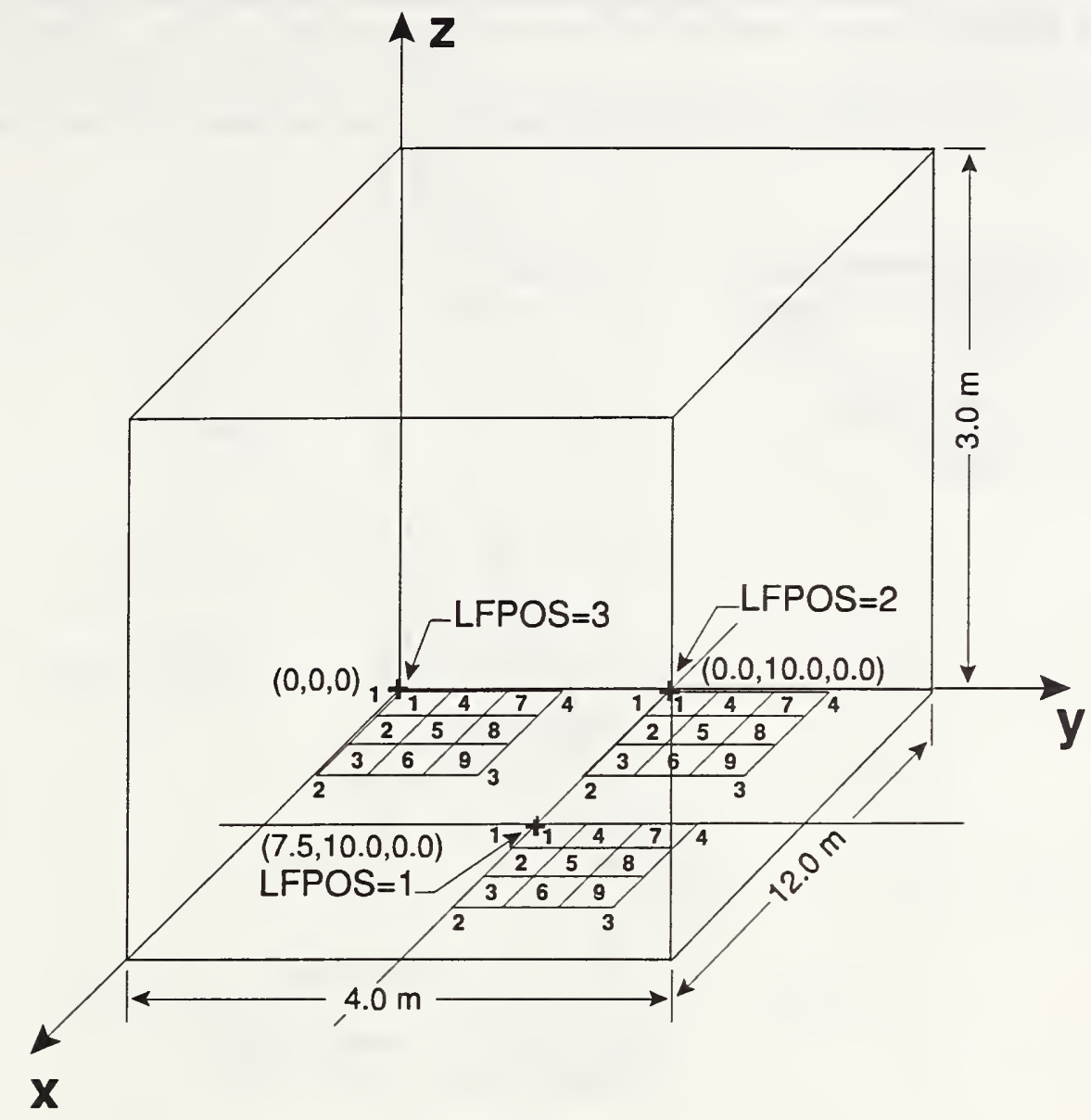

Figure 9 Initial position of a panel (1.0x1.0x0.02) at different fire positions, LFPOS

\footnotetext{
IOPPOS a value of 1 specifies double sided panel a value of 0 specifies single sided panel

THICKM thickness between double sided panel, $m$

NFIRIG number of elements in which to ignite simultaneously

IFIRIG index of surface element in which to ignite the panel fire
}

The orientation of the panel in the room of fire origin using different angles of rotation, $\phi, \theta$, and $\psi$, respectively, is shown in Figure 10 and Figure 11. Figure 10 gives the sequences of the panel positions in response to the effect of the angles of rotation. That is, the panel position $12^{\prime} 3^{\prime} 4^{\prime} 1$ is as a result of the rotation of the panel by the first angle $\phi$ counterclockwise around the z-axis, the second rotation, $\psi$, counterclockwise around the old z-axis (new y-axis) is shown as $12^{\prime \prime \prime} 3^{\prime \prime \prime} 4^{\prime \prime \prime} 1$. Figure 11 shows the initial and final position of the panel in the room of fire origin as a result of the rotation process. Also, it shows the change of the order of surface elements on the panel upon reaching the second position, 12 " 3 " 4" 1 , in Figure 10 as a result of the rotation of the 
panel by the second angle $\theta$ counterclockwise around the $\mathrm{x}$-axis. The elements order is maintained upon reaching the final position as a result of the third angle change of the orientation of the

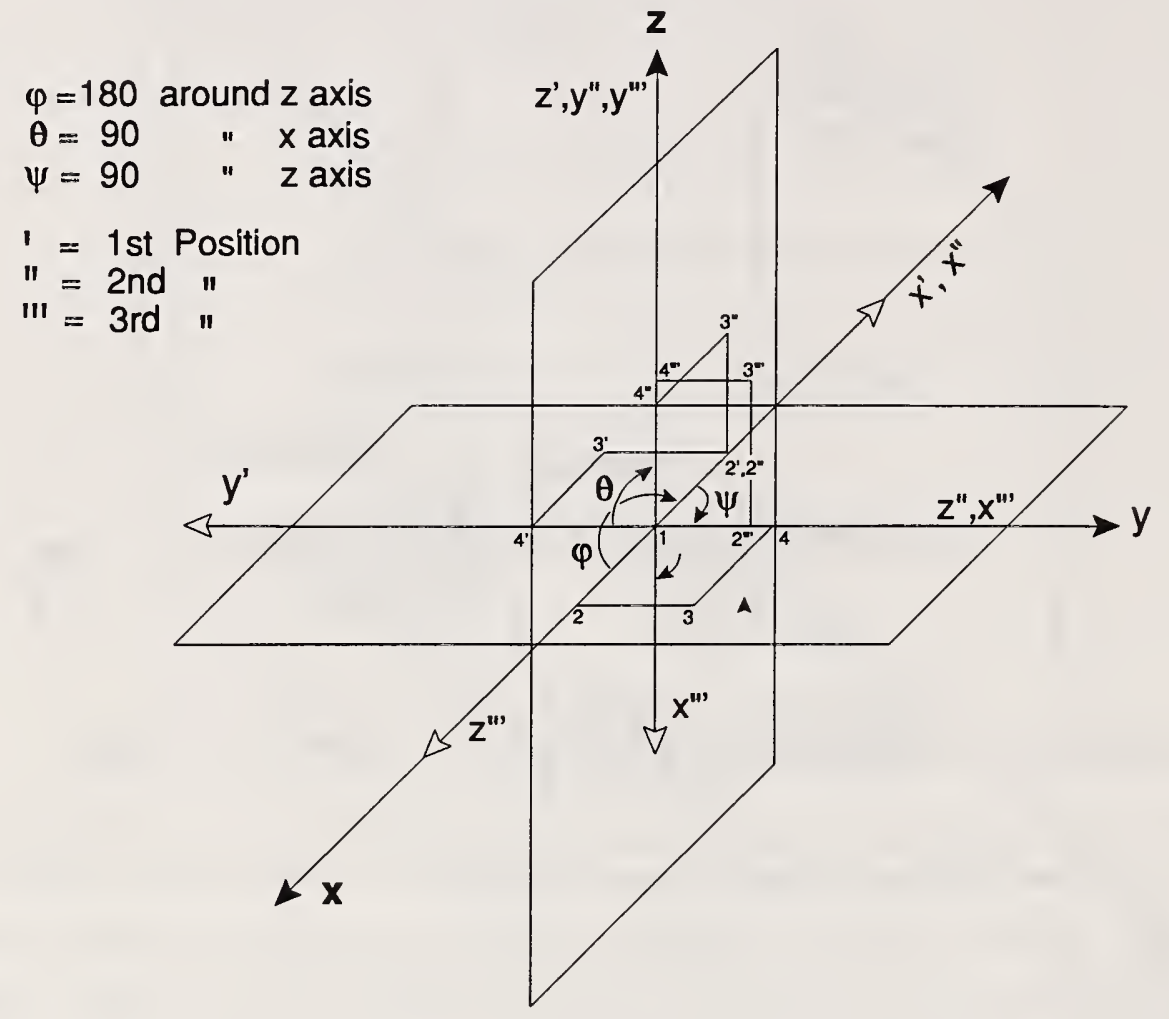

Figure 10 Sequences of panel positions in response to the effect of the angles of rotation $(\phi, \theta, \psi)$

panel. Note that the initial panel should not be merely hinged upwards to a final position in Figure 11, because we wish to orient the burning surface towards the front rather than towards the rear. To verify the correct positions of the panels, the user can select an output option (explained in next section) to provide geometrical details of the final panel position.

\subsection{Bench Database File}

The data for the material thermal, ignition, and flame spread parameters as well as some miscellaneous parameters is the user supplied Bench Database file. The flame spread model reads the data in free format and in the sequential order for the variables defined and listed as follows. 
EMISIV material surface emissivity for eq (52) (should be consistent with TIG below)

AIRAK critical heat release rate ratio of short pool fire to merged pool/wall fire flame shapes (set to 0.0 , as it's unique to furniture fire model)

RSTOCH stoichiometric ratio of fuel to air (used only for surface convective flux of wall fire) RMTMPB room temperature at beginning time, $K$

THRMLT thermal thickness of material for eq (1) (set to 0.0 if using THRMIA only), $\mathrm{kJ} / \mathrm{K} . \mathrm{m}^{2}$

THRMIA thermal inertia of material for eq (2) (set to 0.0 if using THRMLT only), $\mathrm{kW}^{2} / \mathrm{m}^{4} \cdot \mathrm{K}^{2} . \mathrm{sec}$

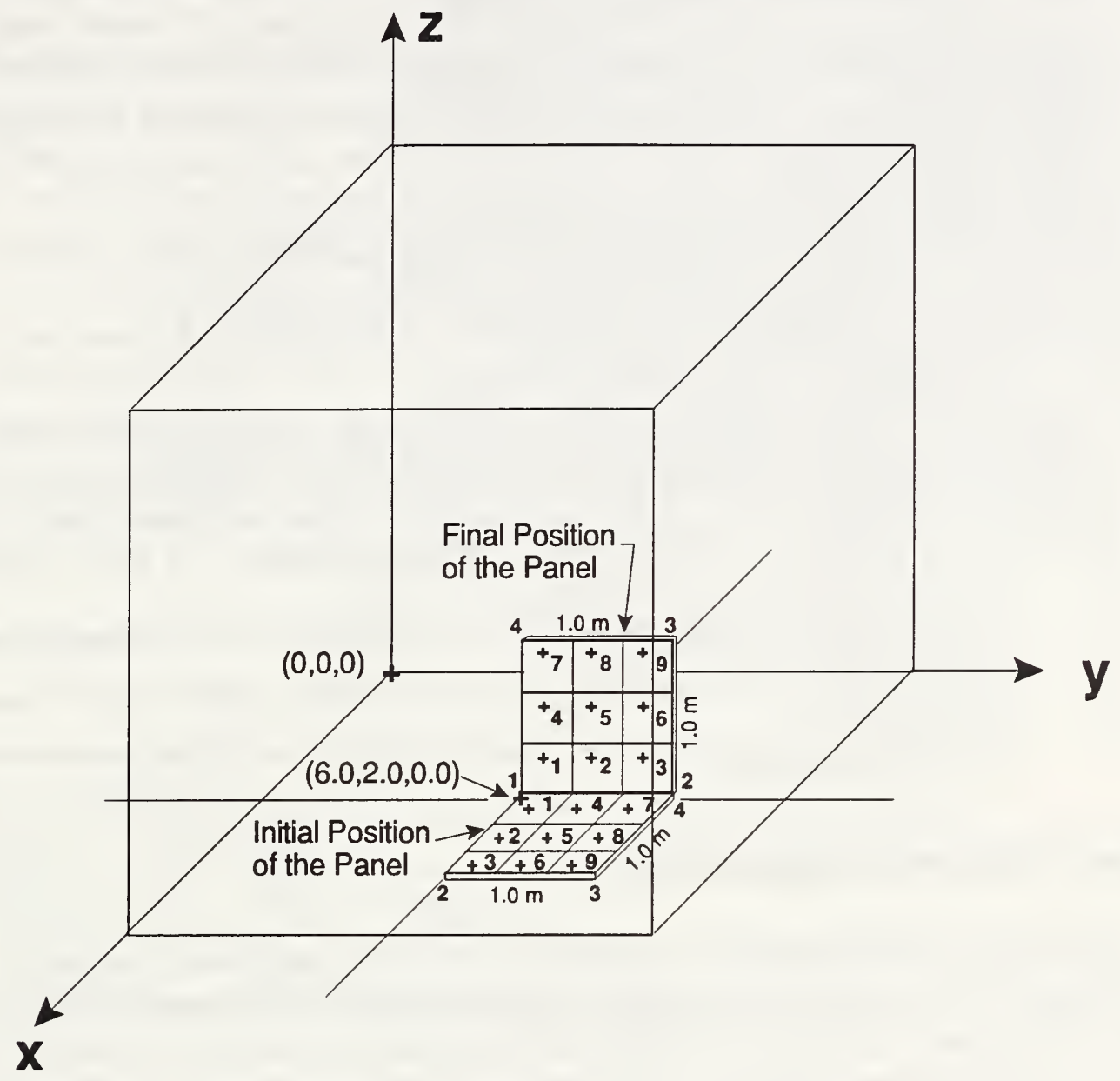

Figure 11. Initial and final positions of the panel $(1.0 \times 1.0 \times 0.02 \mathrm{~m})$ in the room of fire origin $(4.0 \times 12.0 \times 3.0 \mathrm{~m})$.

PDEL characteristic length of exponentially decaying surface radiative flux of adjoining $f(a m e, m$ (nominal value is $0.015 \mathrm{~m}$, but will be computed in newer codes)

TIG piloted ignition temperature of material for eq (14) or (15), $\mathrm{K}$

QCFOOT $q_{f}$, surface convective heat flux of anchored diffusion flame at the flame front, $\mathrm{kW} / \mathrm{m}^{2}$ (nomimal value is $22.5 \mathrm{~kW} / \mathrm{m}^{2}$ for any direction of $\mathrm{flame}$ spread, but will be corrected in newer codes)

FOOTLT $l_{f}$, effective flame foot length in opposed flow for eq (14) or (15), $m$ ( to use LIFT data by using eq (15), set $s_{e}=0$ and compare eq to LIFT formula)

QZERO constant surface heat flux parameter in eq (17) for scaling heat and mass release rates, $\mathrm{kW} / \mathrm{m}^{2}$ (must be calibrated manually by user as explained in section 3.2, but will be automated in newer codes)

SKMAX maximum flaming soot absorption coefficient, $1 / m$ (see Bard \& Pagni for measured values of specific materials, or compare computed soot mass fraction (see Figure 7a) to the corresponding cone calorimeter data of soot production)

XLAM Laser wavelength of the soot optical probe, $\mu \mathrm{m}$ 


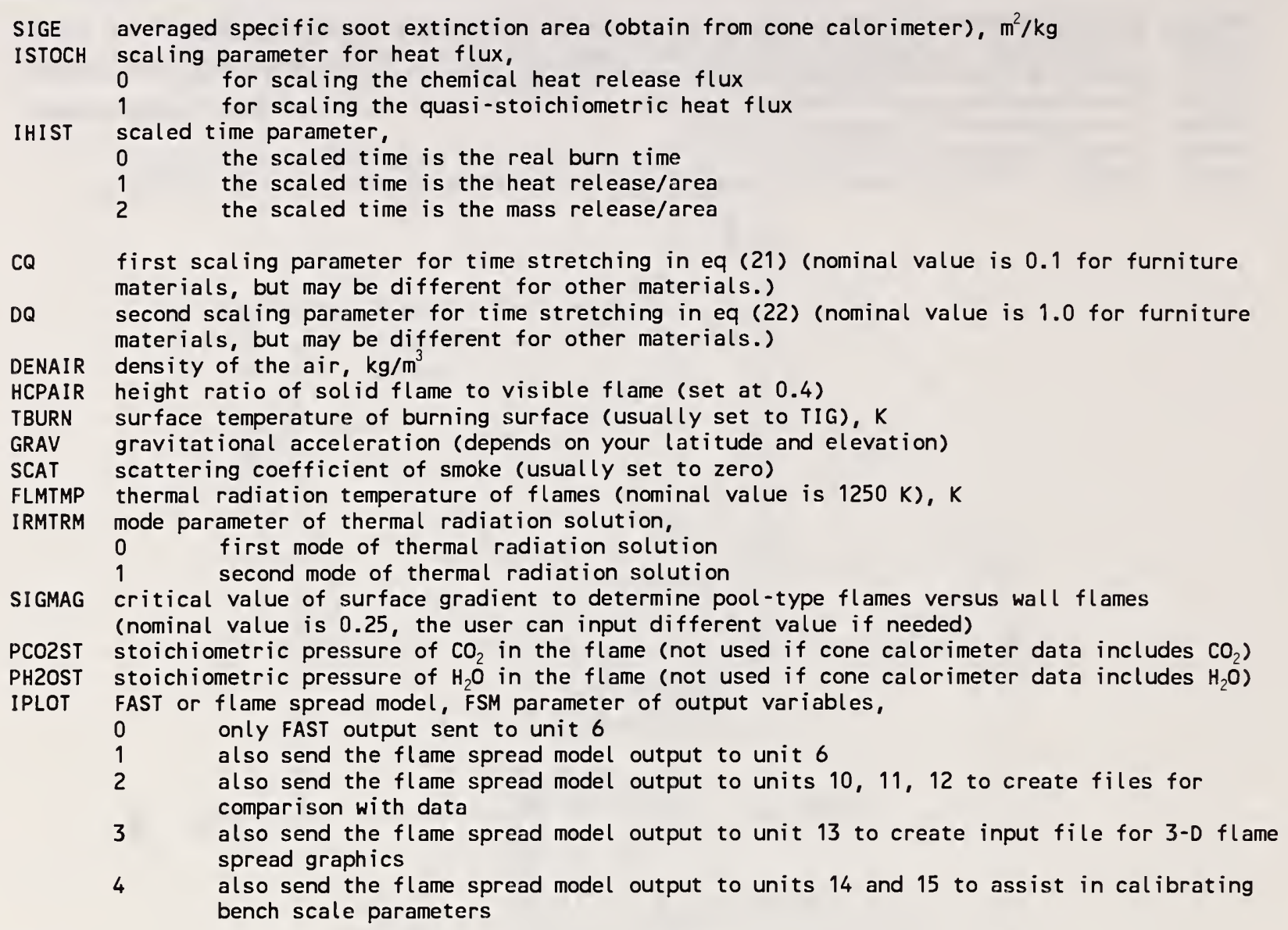

\subsection{Cone Calorimeter Database File}

The cone calorimeter data is supplied by the cone calorimeter apparatus. As the cone calorimeter is upgraded, the format and the content of the cone database are also changed. Therefore, the first line of the cone calorimeter database is inserted by the user to adapt to these various formats. Thus, the user is required to select values for IFRMAT, TSTART, and TEND while the values for QR, IQUAL, and BNTHCK should be contained in the cone database and are required for the flame spread model. Those input variables are defined as follows,

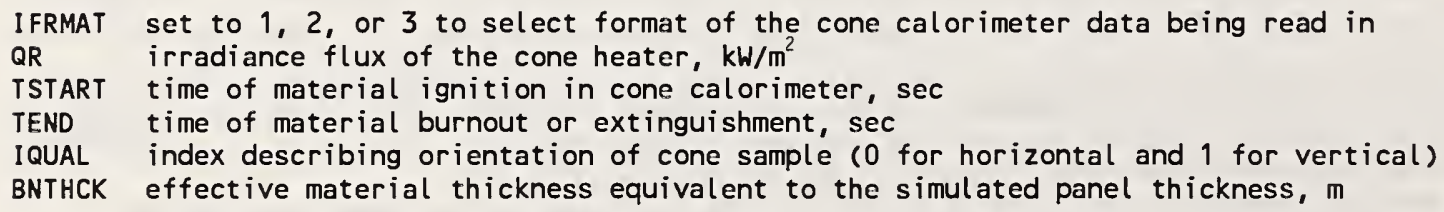

An example of the input data files to the flame spread model is shown in Appendix A. 


\section{APPLICATIONS AND RESULTS}

The flame spread model has been applied to simulate a burning panel of HO/FRPU (heavy Olefin foam material/fire retarded polyurethane) in a single compartment where the fire has been specified as one of the constrained fires (burning is limited by the available oxygen). The simulated panels have different orientations (horizontal panel and vertical walls), different geometries with different thicknesses, and different fire positions in the room of fire origin (center of the room and along a wall of the room) with different ignition locations on the panels. In these applications, the effect of door opening (width and height of the door of the room of fire origin) on the flame spread rate developed on the panel, the pyrolysis rate, and the upper hot gas layer depth has been demonstrated and analyzed. For a full size wall, the simulated wall has slightly smaller width and height $(3.8 \times 2.9 \mathrm{~m})$ than the width and height of the room $(4.0 \times 3.0 \mathrm{~m})$ to avoid some difficulties in viewfactor and Hottel exchange area calculations. The description of the different applications has been summarized as follows:

\subsection{Burning Wall in a Single Compartment}

Compartment geometry: $4.0 \mathrm{~m}$ in width, $12.0 \mathrm{~m}$ in depth, and $3.0 \mathrm{~m}$ in height, Door opening: $1.3 \mathrm{~m}$ in width and $2.0 \mathrm{~m}$ in height,

Fire position in compartment: center of the room, Fire type: constrained fire, Panel material: HO/FRPU (heavy Olefin foam material/fire retarded polyurethane), Panel orientation: vertical wall,

Wall dimension: $3.0 \mathrm{~m}$ in length, $2.0 \mathrm{~m}$ in height, and $0.02 \mathrm{~m}$ in thickness, Ignition location on wall: center of element \#5,

Number of surface elements: 54 ( $9 \times 6$ elements $)$.

\subsection{Burning Horizontal Panel in a Single Compartment}

Compartment geometry: $4.0 \mathrm{~m}$ in width, $12.0 \mathrm{~m}$ in depth, and $3.0 \mathrm{~m}$ in height,

Door opening: $0.25 \mathrm{~m}$ in width and $2.0 \mathrm{~m}$ in height,

Fire position in compartment: along a wall of the room,

Fire type: constrained fire,

Panel material: HO/FRPU (heavy olefin foam material/fire retarded polyurethane),

Panel orientation: horizontal panel,

Panel dimension: $1.0 \mathrm{~m}$ in length, $1.0 \mathrm{~m}$ in width, and $0.1 \mathrm{~m}$ in thickness,

Ignition location on wall: center of element \#5,

Number of surface elements: 9 ( $3 \times 3$ elements).

\subsection{Effect of Door Opening on Burning Wall in a Single Compartment}

\subsubsection{Effect of Door Width}

Compartment geometry: $4.0 \mathrm{~m}$ in width, $12.0 \mathrm{~m}$ in depth, and $3.0 \mathrm{~m}$ in height,

Door opening: Wall 1: $1.3 \mathrm{~m}$ in width and $2.0 \mathrm{~m}$ in height,

Wall 2: $0.25 \mathrm{~m}$ in width and $2.0 \mathrm{~m}$ in height,

Fire position in compartment: along a wall of the room

Fire type: constrained fire 


\section{Calculating Flame Spread on Horizontal and Vertical Surfaces}

Panel material: HO/FRPU (heavy Olefin foam material/fire retarded polyurethane), Panel orientation: vertical wall,

Wall dimension: $3.8 \mathrm{~m}$ in length, $2.9 \mathrm{~m}$ in height, and $0.02 \mathrm{~m}$ in thickness, Ignition location on wal1: center of element \# 4,

Number of surface elements: 35 ( $7 \times 5$ elements).

\subsubsection{Effect of Door Height}

Compartment Geometry: $4.0 \mathrm{~m}$ in width, $12.0 \mathrm{~m}$ in depth, and $3.0 \mathrm{~m}$ in height,

Door opening: Wal1 1: $1.3 \mathrm{~m}$ in width and $2.75 \mathrm{~m}$ in height,

Wa11 2: $1.3 \mathrm{~m}$ in width and $2.0 \mathrm{~m}$ in height,

Fire position in compartment: along a wall of the room

Fire type: constrained fire

Panel material: HO/FRPU (heavy Olefin foam material/fire retarded polyurethane), Panel orientation: vertical wall,

Wal1 dimension: $3.8 \mathrm{~m}$ in length, $2.9 \mathrm{~m}$ in height, and $0.02 \mathrm{~m}$ in thickness, Ignition location on wall: center of element \#4,

Number of surface elements: 35 ( $7 \times 5$ elements).

Figure 12 shows the result of flame spreading over a horizontal panel surface. The flame spread contours start at time zero at the center of the panel where the piloted ignition has been initiated. The horizontal flame spread contours approach the panel edges in all directions. The simulated panel considered is a horizontal $1.0 \mathrm{~m}$ square panel (with 9 surface elements) located at the center of the room of fire origin. The

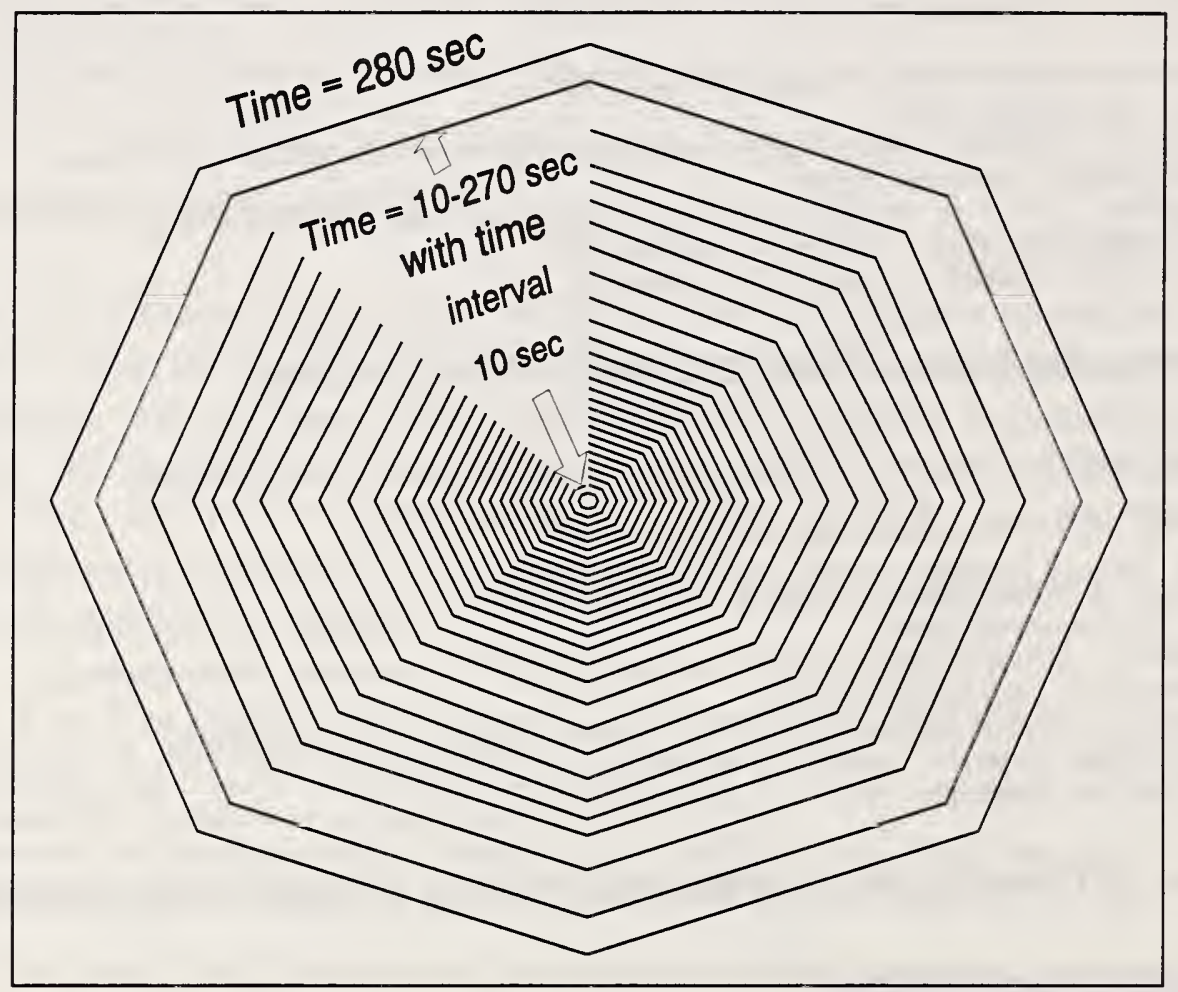

Figure 12. Flame spread contours on a thick horizontal panel $(1.0 \times 1.0 \times 0.1 \mathrm{~m})$ 
flame spread on the panel initially proceeded at a minimum rate as shown by the growth of the burning polygons on the panel and then accelerated toward the panel edges as a result of radiative heating from the fire plume and the growing upper gas layer. Once the flame spread contours completely cover the panel, the whole panel is on fire. At this time, the fire experienced its greatest growth rate as indicated by the heat and mass release rates. The flame spreading process has nearly finished and the continued fire growth is resulting from the increasing flame radiative heat feedback to the burning surfaces. Eventually, the fire growth reaches a limit dictated either by the flame soot volume fraction reaching its maximum value for the given flame base radius or by the burnout of some surface elements. While the panel surface is burning, the flame spread contours begin to recede into the cushion thickness until the whole panel material is burned out. When the flame spread polygon is finally shifted by an amount equal to the virgin material thickness, the panel no longer supports pyrolysis.

The flame spread model predictions for the burning walls of a thin material (of HO/FRPU) with different wall sizes and under the effect of various vent configurations (door opening) are shown in Figure 13 through Figure 17. In Figure 13 and Figure 14, the flame spread contours for small and full size walls are shown, while Figure 15 and Figure 16 demonstrate the effect of door opening on the hot gas layer depth. Figure 17 shows the corresponding pyrolysis rates of the wall material under the effect of different door openings.

Figure 13 shows the flame spread contours for a $3.0 \times 2.0 \mathrm{~m}$ thin wall with the ignition located in the middle and $0.1667 \mathrm{~m}$ from the wall bottom (center of element \# 5). As shown in this figure, flame spread from a piloted ignition source moves up rapidly until it reaches the top of the wall, and then moves sideways at the top in an accelerated fashion due to radiative heating from the growing upper gas layer. Convective preheating of the combustible wall by the upper gas layer is assumed small because the lower gas layer is entrained into the wall fire plume. This rapid rise in the flame spread rate from $320 \mathrm{~s}$ to $380 \mathrm{~s}$ is followed by a drop in the flame spread rate at about $380 \mathrm{sec}$. The deceleration of the flame spread from $380 \mathrm{~s}$ to $520 \mathrm{~s}$ is due to much lowered preheating of virgin elements below the upper gas layer. This in turn caused lower surface temperatures which resulted in reduced values of fiame spread velocity. By that time, most burning elements were burned out and the flame spreading process was nearly complete.

The effects of the door opening (both width and height) on the flame spread rate over the wall, depth of the hot gas layer, and pyrolysis rate are shown in Figure 14 through Figure 17. Figure 14 shows the predicted contours of flame spread on a full size wall in a room with fully opened door. Changing the door opening has a negligible effect on the predicted flame spread. However, the door opening has a pronounced effect on the upper gas layer depth as can be seen from Figure 15 and Figure 16. In Figure 15, the narrow door opening $(0.25 \mathrm{~m})$ results in a deeper hot gas layer than for the fully 
opened door $(1.3 \mathrm{~m})$. In Figure 16, the door opening of lower height $(2.0 \mathrm{~m})$ results in

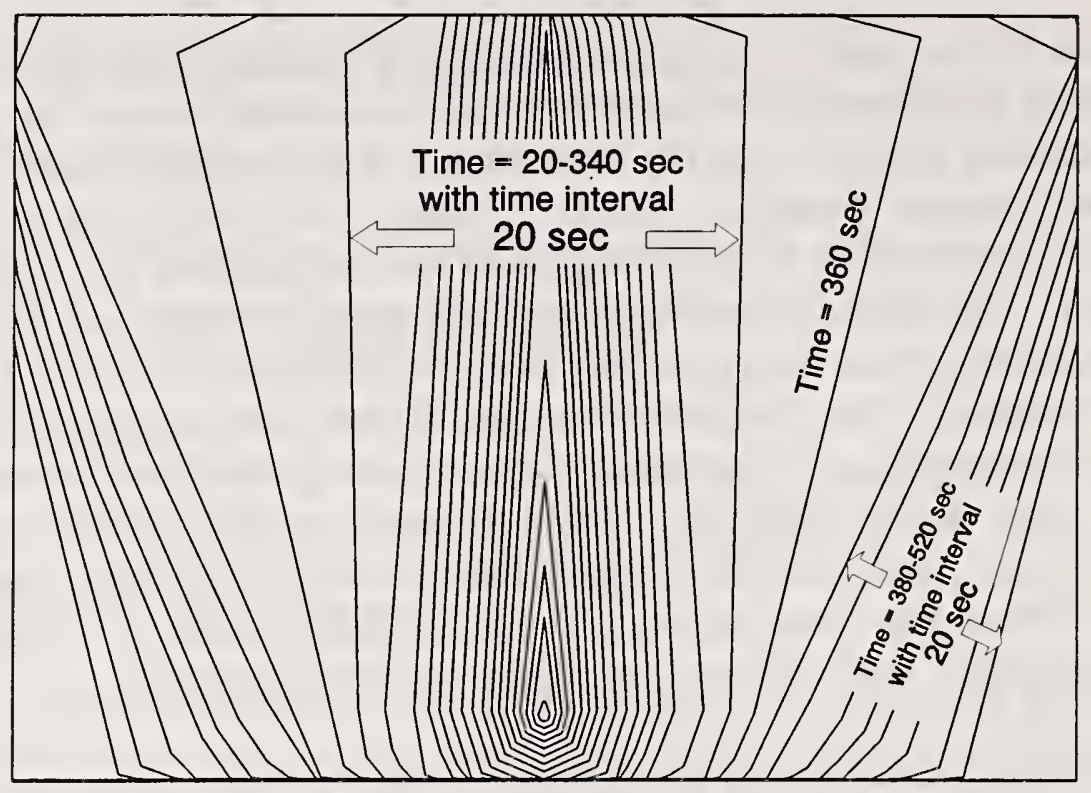

Figure 13 Flame spread contours on a thin wall $(3.0 \times 2.0 \times 0.02 \mathrm{~m})$ as a function of time.

a deeper upper gas layer than of that of the door of higher soffit $(2.75 \mathrm{~m})$. The

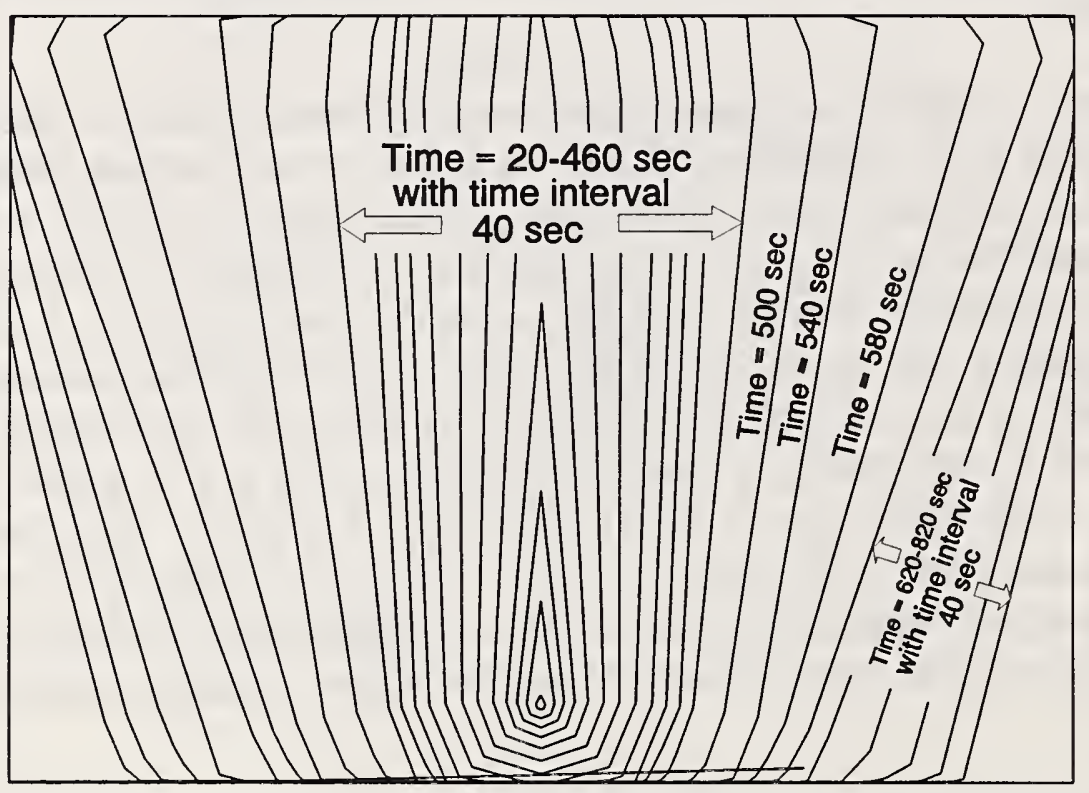

Figure 14. Flame spread contours on a full size thin wall $(3.8 \times 2.9 \times 0.02 \mathrm{~m})$ as a function of time.

corresponding effect of door opening height on the pyrolysis rate is shown in Figure 17. The lower the top of the door, the higher the pyrolysis rate of the burning wall. 
Figure 16 and Figure 17 also show that the time to reach the maximum depth of the hot gas layer (lowest interface height) approximately coincides with the peak in the pyrolysis release of the burning

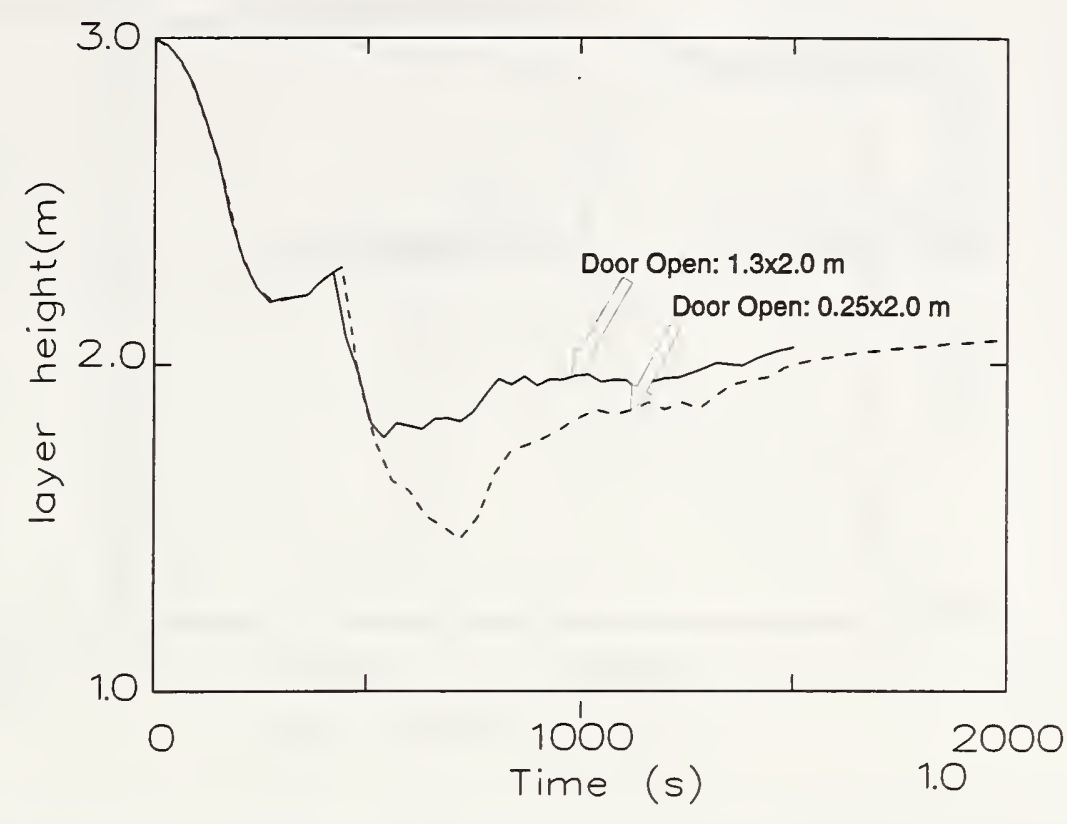

Figure 15. Effect of door opening width on the depth of hot gas layer in the room of fire origin as a result of burning of a full size thin wall.

rate wall material. Varying door opening, both the hot gas layer depth and the pyrolysis rate of each case have reached their limiting values, which is an important modeling feature.

\section{CONCLUSIONS}

The flame spread model provides a challenging range of predicted values for the flame spread rates on panels, heat and pyrolysis rates, and hot gas layer depths and temperatures which are influenced by many factors, such as, geometry, orientation, and vent configuration (door opening). In all applications, the flame spread is allowed to proceed in any direction on the panel. Also, the flame spread velocities and the shape of the flame spread contours vary with panel orientation (horizontal and vertical panels). On horizontal panels the flame spreading in opposed flow accelerates due to radiant preheating and the flame spread contours retain a regular octogon shape. On the vertical panels the flame spreading along the direction of the fire plume accelerates much more than the flame spreading in other directions to cause a tear-drop shaped burning area. After reaching the ceiling, the flame spreading in opposed flow dominates the fire growth and accelerates along the top of the wall due to surface radiant preheating by the upper 


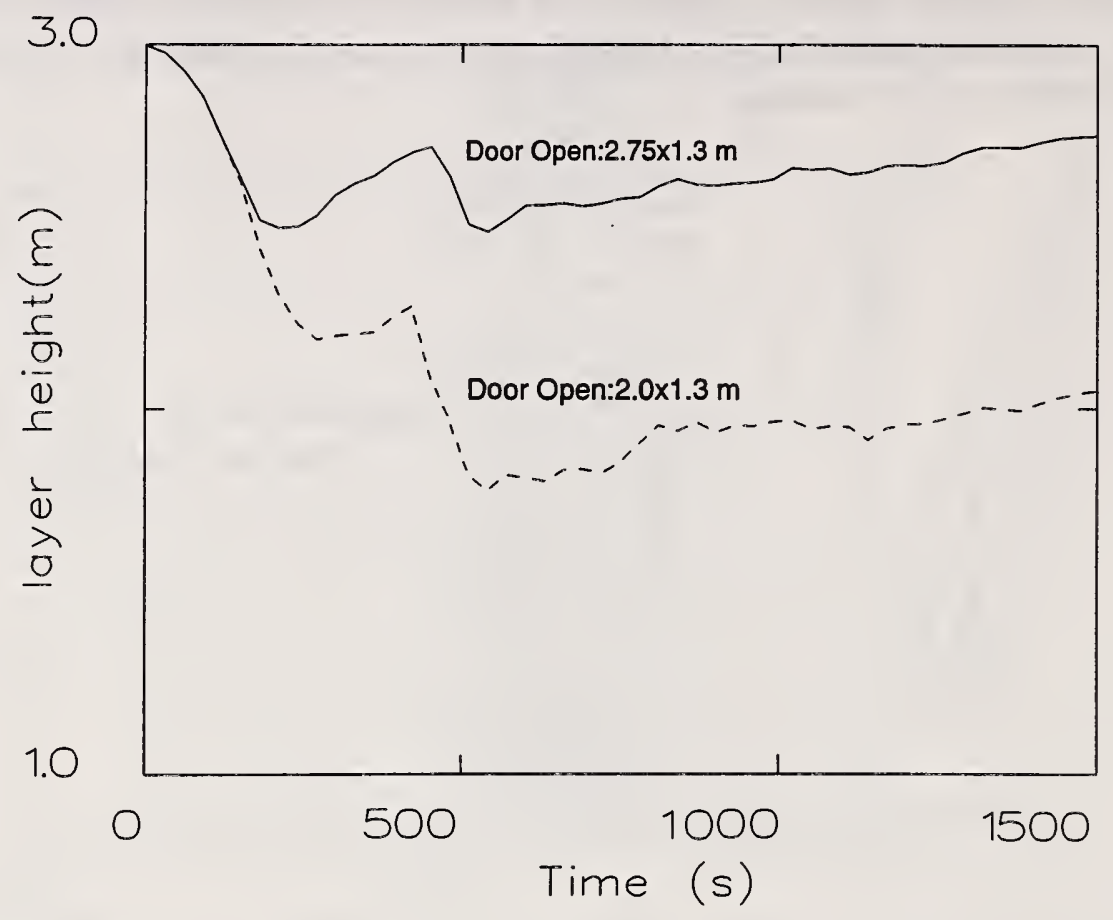

Figure 16. Effect of door opening height on the depth of hot gas layer in the room of fire origin as a result of burning of a full size thin wall.

gas layer.

The results demonstrate that formulation of the flame spread with radiative heating is essential to the prediction of the fire spread in a compartment. Significant radiative heating from the growing upper gas layer contributes to accelerative heat and mass release rates. The accelerative growth of the fuel pyrolysis rate is due to two main competing factors: the rate of increase of number of burning surface elements on the simulated horizontal panel or wall and the rate of increase of the surface radiative heat flux. Eventually, a maximum value of the fuel pyrolysis rate is reached and then its rate of decrease is controlled by the burnout of the surface elements. While the surface is burning, the local burning rate will result in material degradation. As materials become depleted, the burnout boundaries are advanced. In other words, the mass loss parameter is a direct indication of the panel's deterioration due to fire, and will lead to the determination of the length of time it will take for the element to develop a hole. This, in turn, will provide a tool for evaluating the effectiveness of the member as a fire barrier.

Despite the significant effect of the vent configuration on the hot gas layer depth, there does not seem to be a corresponding effect on the history of flame spreading on the walls in these cases. This effect may be an artifact of a flame spread logic that permits only obtuse vertex angles on the burning polygons, or the surface elements may be too large. Also, the effects which vitiated combustion can have on flame spread have not been investigated. This paper has addressed only the modeling aspects. Comparisons 


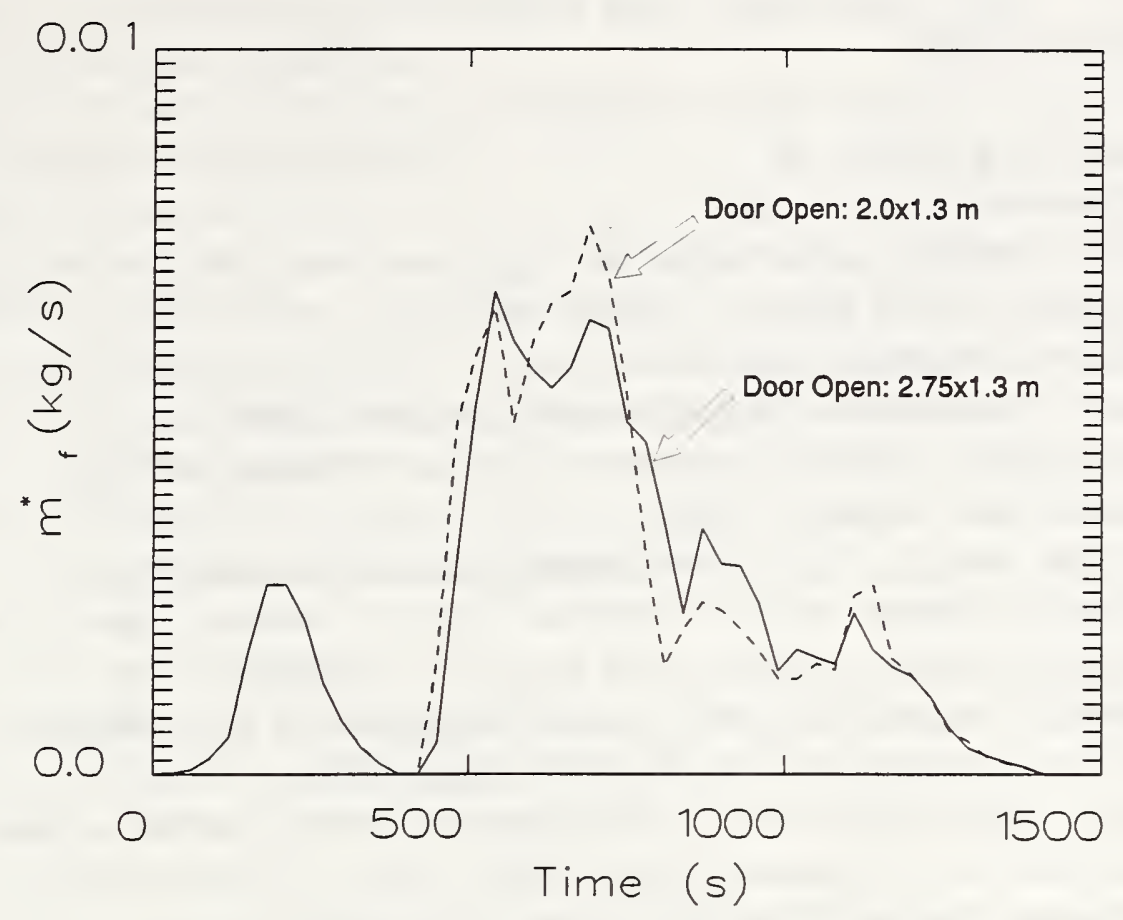

Figure 17. Effect of door opening height on the pyrolysis rate in the room of fire origin as a result of burning of a full size thin wall.

with experimental data is being done elsewhere [29].

For example, the fire growth on a four-cushion mockup of a chair was simulated using the databases described in the User's Guide for FAST/FFM Version 3 [30]. The model was validated with fire tests for a 4-cushion mockup fire with three different fabric/foam cushion types. The comparison include: (1) burn area fractions of each cushion as a function of time, (2) burn rate of the mockup as a function of time with fire test data from the furniture calorimeter, (3) mass loss rate of the furniture as a function of time, and (4) the overall levels of soot production [31]. The model compared very well with the furniture calorimeter data. It did require minor re-calibration of the scaling constants.

Bench scale data, needed by the FSM for scaling, are available for both thick and thin horizontal panels, but only for thin vertical panels. This is a limitation in applying the flame spread model for walls of different thicknesses. Using the available input database of thin material in simulating large thick walls leads to a large change in the radiative power emission of the upper gas layer and absurd values of the view factor calculations. This in turn causes oscillations in the upper gas layer temperatures. For the materials with short burning histories and on large surface elements, the model simulates unrealistic short spiking burn rates as function of time. This is caused by the flame spread area not reaching additional wall surface elements before the burning elements burn out. 


\section{NOMENCLATURE}

$\mathrm{A}_{\mathrm{b} \gamma} \quad$ bounding gas area, $\mathrm{m}^{2}$

$A_{i} \quad$ surface element area, $m^{2}$

$\mathrm{A}_{\gamma} \quad$ flame bounding surface area, $\mathrm{m}^{2}$

$\mathrm{A}_{\mathrm{p}} \quad$ projected area of gaseous volume, $\mathrm{m}^{2}$

$\mathrm{a}_{\gamma} \quad$ effective absorption coefficient, $1 / \mathrm{m}$

$\mathrm{C}_{\mathrm{up}}$ mass concentration of soot in upper gas layer, $\mathrm{kg} / \mathrm{m}^{3}$

$\mathrm{C}_{\mathrm{p}, \mathrm{v}}$ heat capacity (constant pressure or constant volume), $\mathrm{W} / \mathrm{kg} \cdot \mathrm{K}$

$\mathrm{C}$ material heat capacity, $\mathrm{J} / \mathrm{g} \cdot \mathrm{K}$

$\mathrm{C}_{\mathrm{pa}} \quad$ air heat capacity, $\mathrm{J} / \mathrm{g} \cdot \mathrm{K}$ (determined at standard atmosphere)

D hydraulic diameter of the flame base, $m$

$\dot{\mathrm{e}}_{\mathrm{i}} \quad$ blackbody surface radiative heat flux $\left(\sigma \mathrm{T}_{\mathrm{si}}{ }^{4}\right), \mathrm{kW} / \mathrm{m}^{2}$

$\dot{\mathrm{e}}_{\gamma} \quad$ elemental volume blackbody radiative heat flux $\left(\sigma \mathrm{T}_{\mathrm{g}}{ }^{4}\right), \mathrm{kW} / \mathrm{m}^{2}$

$\mathrm{F}_{\mathrm{a}} \quad$ radiation factor defined by Bard and Pagni [20]

$F_{i, \gamma} \quad$ configuration factor between the flame surface $A_{\gamma}$ and the surface area, $A_{i}$

$F_{i} \quad$ mass fraction of combustion product, $i$

$\mathrm{F}_{\mathrm{s} \text {, exit }}$ soot mass fraction of fuel from cone calorimeter

$\mathrm{F}_{\mathrm{CO}} \quad$ carbon monoxide mass fraction of fuel

$\mathrm{G}$ time stretching parameter in eq ?

$\mathrm{Gr}_{\mathrm{x}} \quad$ Grashof number

g gravitational acceleration, $\mathrm{m} / \mathrm{s}^{2}$

$\mathrm{g}_{\mu} \mathrm{g}_{\gamma}$ exchange area between the volume $\mathrm{V}_{\mu}$ and the volume $\mathrm{V}_{\gamma}, \mathrm{m}^{2}$

$\mathrm{g}_{\gamma} \mathrm{s}_{\mathrm{i}} \quad$ exchange area between the volume $\mathrm{V}_{\gamma}$ and the surface $\mathrm{A}_{\mathrm{i}}, \mathrm{m}^{2}\left(\mathrm{~s}_{\mathrm{i}} \cdot \mathrm{g} \gamma\right.$ is equivalent)

$\mathrm{H}_{\mathrm{c}} \quad$ heat of reaction of carbon, $\mathrm{kJ} / \mathrm{kg}$

$\mathrm{H}_{\mathrm{co}} \quad$ heat of reaction of carbon monoxide, $\mathrm{kJ} / \mathrm{kg}$

$\mathrm{H}_{\mathrm{f}} \quad$ effective heat of pyrolysis (inverse of $\dot{\mathrm{m}}^{*}$ ), $\mathrm{kJ} / \mathrm{kg}$

$\mathrm{h}$ linearized heat transfer coefficient, $\mathrm{kW} / \mathrm{m}^{2} \cdot{ }^{\circ} \mathrm{K}$

$h_{c} \quad$ convective heat transfer coefficient, $\mathrm{kW} / \mathrm{m}^{2} \cdot{ }^{\circ} \mathrm{K}$

$\dot{\mathrm{h}}_{\text {cone }} \quad$ chemical heat release flux from cone calorimeter, $\mathrm{kW} / \mathrm{m}^{2}$

$\dot{\mathrm{h}}_{\mathrm{i}} \quad$ incoming surface radiative heat flux, $\mathrm{kW} / \mathrm{m}^{2}$

$\dot{\mathrm{h}}_{\gamma} \quad$ incoming elemental volume radiative heat flux, $\mathrm{kW} / \mathrm{m}^{2}$

$h_{p} \quad$ effective heat transfer coefficient in a pool fire, $\mathrm{kW} / \mathrm{m}^{2} \cdot{ }^{\circ} \mathrm{K}$

$h_{\mathrm{r}} \quad$ radiative heat transfer coefficient, $\mathrm{kW} / \mathrm{m}^{2}{ }^{\circ} \mathrm{K}$

$\dot{\mathrm{h}}^{*} \quad$ scaled heat release flux

$\dot{\mathrm{h}}_{\mathrm{st}} \quad$ quasi-stoichiometric heat release flux, $\mathrm{kW} / \mathrm{m}^{2}$

$\mathrm{k}$ material thermal conductivity, $\mathrm{kW} / \mathrm{m} \cdot{ }^{\circ} \mathrm{K}$

$\mathrm{k}_{\mathrm{a}} \quad$ air thermal conductivity, $\mathrm{kW} / \mathrm{m} \cdot{ }^{\circ} \mathrm{K}$

$\mathrm{k}_{\mathrm{s}, \text { flame }}$ soot absorption coefficient in flame, $\mathrm{m}^{-1}$

$\mathrm{k}_{\mathrm{s}, \max }$ maximum soot absorption coefficient for the material, $\mathrm{m}^{-1}$

$\mathrm{k}_{\mathrm{s} \text {, up }}$ mean soot extinction coefficient in upper gas layer, $\mathrm{m}^{-1}$

$\mathrm{k}_{\mathrm{up}} \quad$ laser soot extinction coefficient in upper gas layer, $\mathrm{m}^{-1}$

$\mathrm{k}_{\gamma} \quad$ gas zone extinction coefficient, $\mathrm{m}^{-1}$

$\mathrm{L}$ mean beam length, $\mathrm{m}$ 
$\mathrm{L}_{\mathrm{f}} \quad$ convective contribution to the effective heat of pyrolysis, $\mathrm{kJ} / \mathrm{kg}$

$l_{\mathrm{f}} \quad$ conductive thermal length, $\mathrm{m}$

$l_{\mathrm{i}, \gamma} \quad$ distance from surface element $\mathrm{A}_{\mathrm{i}}$ to gaseous volume centroid, $\mathrm{m}$

$l_{\mathrm{p}} \quad$ plume radiative thermal length, $\mathrm{m}$

$\mathrm{M}_{\text {fuel }}$ fuel mass release rate, $\mathrm{kg} / \mathrm{s}$

$\dot{\mathrm{M}}_{\mathrm{g}} \quad$ flowing gaseous zone mass rate, $\mathrm{kg} / \mathrm{s}$

$\dot{\mathrm{M}}_{\mathrm{j}} \quad$ combustion product mass rate, $\mathrm{kg} / \mathrm{s}$

$\dot{\mathrm{m}}^{*} \quad$ scaled fuel release flux, $\mathrm{kg} / \mathrm{kJ}$

m" material mass loss flux in cone calorimeter, $\mathrm{kg} / \mathrm{m}^{2} \cdot \mathrm{s}$

$\mathrm{P}_{\text {air }} \quad$ ambient air pressure, atm

$\mathrm{P}_{\mathrm{CO} 2}$ partial vapor pressure of carbon dioxide, atm

$\mathrm{P}_{\mathrm{H} 2 \mathrm{O}}$ partial vapor pressure of water vapor, atm

$\operatorname{Pr}$ ambient Prandtl's number (0.72)

$\dot{Q}$ heat release rate of fire, $\mathrm{kW}$

$\dot{Q}_{c} \quad$ total heat release rate of flame, $\mathrm{kW}$

$\mathrm{Q}_{\mathrm{s}, \mathrm{i}} \quad$ surface net radiative source power, $\mathrm{kW}$

$\mathrm{Q}_{\mathrm{v}, \gamma} \quad$ net radiative volume source power, $\mathrm{kW}$

$\dot{\mathrm{Q}}_{\gamma} \quad$ volume radiative source power, $\mathrm{kW}$

Q" heat per unit area used in the time scaling, $\mathrm{kJ} / \mathrm{m}^{2}$

$\mathrm{q}_{\mathrm{c}} \quad$ surface convective heat flux, $\mathrm{kW} / \mathrm{m}^{2}$

$\mathrm{q}_{\mathrm{f}} \quad$ gaseous surface conductive heat flux at flame front, $\mathrm{kW} / \mathrm{m}^{2}$

$\mathrm{q}_{\mathrm{o}} \quad$ scaled heat flux constant parameter, $\mathrm{kW} / \mathrm{m}^{2}$

$\mathrm{q}_{\mathrm{r}} \quad$ net surface radiative heat flux, $\mathrm{kW} / \mathrm{m}^{2}$

$\mathrm{q}_{\mathrm{re}} \quad$ surface radiant fluxes from external sources, $\mathrm{kW} / \mathrm{m}^{2}$

$\mathrm{q}_{\mathrm{rf}}$ surface radiative heat flux from attached flame, $\mathrm{kW} / \mathrm{m}^{2}$

$\mathrm{q}_{\mathrm{ri}} \quad$ surface radiative heat flux from cone heater, $\mathrm{kW} / \mathrm{m}^{2}$

$\mathrm{q}_{\mathrm{s}} \quad$ net surface heat flux, $\mathrm{kW} / \mathrm{m}^{2}$

$\mathrm{R}_{\mathrm{g}} \quad$ partial gas constant

$\mathrm{r} \quad$ hydraulic radius of a flame base, $\mathrm{m}$

$\mathrm{r}_{\mathrm{f}} \quad$ stoichiometric fuel/air ratio

$\mathrm{r}_{\mathrm{i}, \gamma} \quad$ distance from the surface element to a point on the flame bounding surface, $\mathrm{m}$

$\mathrm{r}_{\gamma} \quad$ distance between the flame base center and a "center of radiation" of the flame, $\mathrm{m}$

$\mathrm{S}_{\mathrm{i} \gamma} \quad$ distance from a point in $\mathrm{A}_{\mathrm{i}}$ to a point inside $\mathrm{V}_{\gamma}, \mathrm{m}$

$\mathrm{s} \quad$ surface distance from the flame front, $\mathrm{m}$

$\mathrm{s}_{\mathrm{e}} \quad$ preheated distance, $\mathrm{m}$

$s_{j} s_{i} \quad$ exchange area between surface $A_{j}$ and the surface $A_{i}, m^{2}$

$\mathrm{T}^{*} \quad$ scaled time (effective heat release per area), $\mathrm{kJ} / \mathrm{m}^{2}$

$\mathrm{T}_{\infty} \quad$ ambient temperature, ${ }^{\circ} \mathrm{K}$

$\mathrm{T}_{\mathrm{b}} \quad$ temperature of burning surface, ${ }^{\circ} \mathrm{K}$

$\mathrm{T}_{\mathrm{e}} \quad$ preheated surface temperature, ${ }^{\circ} \mathrm{K}$

$\mathrm{T}_{\mathrm{eq}} \quad$ surface equilibrium temperature, ${ }^{\circ} \mathrm{K}$

$\mathrm{T}_{\mathrm{f}} \quad$ flame temperature for thermal radiation, ${ }^{\circ} \mathrm{K}$

$\mathrm{T}_{\mathrm{g}}$ gaseous zone temperature, ${ }^{\circ} \mathrm{K}$

$\mathrm{T}_{\mathrm{ig}} \quad$ surface ignition temperature, ${ }^{\circ} \mathrm{K}$

$\mathrm{T}_{s} \quad$ material surface temperature, ${ }^{\circ} \mathrm{K}$ 
$\mathrm{T}_{\mathrm{o}} \quad$ initial surface temperature, ${ }^{\circ} \mathrm{K}$

$\mathrm{t}$ time, $\mathrm{s}$

$\mathrm{V}_{\mathrm{a}} \quad$ opposed air speed at flame front, $\mathrm{m} / \mathrm{s}$

$\mathrm{V}_{\mathrm{f}} \quad$ flame front quasi-steady speed, $\mathrm{m} / \mathrm{s}$

$\dot{V}_{\mathrm{p}} \quad$ fire plume volumetric flow rate, $\mathrm{m}^{3} / \mathrm{s}$

$\mathrm{V}_{\gamma} \quad$ isothermal finite volume, $\mathrm{m}^{3}$

$\dot{\mathrm{w}}_{\mathrm{i}} \quad$ outgoing surface radiative heat flux, $\mathrm{kW} / \mathrm{m}^{2}$

$\dot{\mathrm{w}}_{\gamma} \quad$ outgoing elemental volume radiative heat flux, $\mathrm{kW} / \mathrm{m}^{2}$

$\mathrm{x}$ surface distance in flaming boundary layer, $\mathrm{m}$

$\mathrm{Y}_{\mathrm{w}} \quad$ wall pyrolysis zone width, $\mathrm{m}$

y dimensionless fuel release flux in eq Figure 5

$\mathrm{Z}_{\mathrm{f}} \quad$ average visible pool $\left(\mathrm{f}^{\mathrm{p}}\right)$ or wall $\left(\mathrm{f}^{\mathrm{w}}\right)$ fire height, $\mathrm{m}$

$\mathrm{Z}_{\mathrm{w}} \quad$ wall pyrolysis zone length, $\mathrm{m}$

$\delta \quad$ effective thickness of a material, $\mathrm{m}$

$\delta_{1} \quad$ wall flame laminar boundary layer thickness, $\mathrm{m}$

$\delta_{\mathrm{t}} \quad$ wall flame turbulent boundary layer thickness, $\mathrm{m}$

$\epsilon_{\mathrm{CO} 2}$ carbon dioxide gaseous emissivity

$\epsilon_{\mathrm{D}} \quad$ emissivity correction due to $\mathrm{CO} 2$ and $\mathrm{H} 2 \mathrm{O}$ band overlap

$\epsilon_{\mathrm{g}}$ gaseous emissivity due to $\mathrm{CO} 2$ and $\mathrm{H} 2 \mathrm{O}$

$\epsilon_{\mathrm{H} 2} \mathrm{O}$ water vapor gaseous emissivity

$\epsilon_{\mathrm{i}} \quad$ surface element emissivity

$\epsilon_{\mathrm{s}} \quad$ gaseous zone or flaming soot emissivity

$\epsilon_{\mathrm{T}} \quad$ total gaseous zone emissivity

$\phi \quad$ inclined surface angle of wall fire

$\lambda \quad$ wavelength, $m$

$\mu_{\infty} \quad$ ambient viscosity, $\mathrm{kg} / \mathrm{m} \cdot \mathrm{s}$

$\nu_{\infty} \quad$ ambient kinematic viscosity, $\mathrm{m}^{2} / \mathrm{s}$

$\omega_{\gamma} \quad$ volume scattering coefficient

$\rho \quad$ material density, $\mathrm{kg} / \mathrm{m}^{3}$

$\rho_{\mathrm{a}} \quad$ air density, $\mathrm{kg} / \mathrm{m}^{3}$

$\rho_{\mathrm{i}} \quad$ surface element diffused reflectivity

$\sigma \quad$ Stefan-Boltzman constant, $\mathrm{kW} / \mathrm{m}^{2} \cdot{ }^{\circ} \mathrm{K}^{4}$

$\sigma_{\mathrm{p}}^{\mathrm{e}} \quad$ specific soot extinction area, $\mathrm{m}^{2} / \mathrm{kg}$

$\sigma_{\mathrm{s}}^{\mathrm{e}} \quad$ soot extinction area per unit soot mass, $\mathrm{m}^{2} / \mathrm{kg}$

$\tau$ transmissivity (dimensionless)

$\theta_{\mathrm{i}, \gamma} \quad$ angle between the surface element normal vector and the distance vector from the centroid of the $\mathrm{V}_{\gamma}$ to the surface element 


\section{REFERENCES}

[1] Jones, W. W., A Multicompartment Model for the Spread of Fire, Smoke and Toxic Gases, Fire Safety Journal 9, 55 (1985).

[2] Dietenberger, M. A., "Mathematical Modeling of Furniture Fires," NBS-GSR-86-506, February, 1986.

[3] Standard Test Method for Heat and Visible Smoke Release Rates for Materials and Products Using an Oxygen Consumption Calorimeter (E 1354). American Society for Testing and Materials, Philadelphia, PA.

[4] Standard Test Method for Determining Material Ignition and Flame Spread (ASTM E 1321 - LIFT), American Society for Testing and Materials, Philadelphia, PA 19103 (1990).

[5] Harkleroad, M., Quintiere, J., and Walton, W., "Radiative Ignition and Opposed Flow Flame Spread Measurements on Materials, " DOT/FAA/CT-83-28, August 1983.

[6] Dietenberger, M. A., "Piloted Ignition and Flame Spread on Composite Solid Fuels in Extreme Environments," Ph. D. Thesis, University of Dayton, 1991.

[7] Mitler, H. B. and Emmons, H. W., "Documentation for CFC V, the Fifth Harvard Computer Fire Code, " NBS-GCR-81-344, Oct. 1981.

[8] deRis, J. N., "Spread of a Laminar Diffusion Flame," 12th Symposium (International) on Combustion, The Combustion Institute, pp. 241-252, 1969.

[9] Fernandez-Pello, A. K., Ray, S. R., and Glassman, I., "Flame Spread in an Opposed Flow: The Effect of Ambient Oxygen Concentration, "18th Symposium (International) on Combustion, The Combustion Institute, pp. 579-589, 1981.

[10] Altenkirch, R. A., Eichhorn, R., and Shang, P. C., "Buoyancy Effect of Flames Spreading down Thermally Thin Fuels, "Combustion and Flame, Vol. 37, pp. 7183, 1980.

[11] Altenkirch, R. A., Eichhorn, R., and Rizni, H. R., "Correlating Downward Flame Spread Rates for Thick Fuel Beds," Combustion Science and Technology, Vol. 32, pp. 49-66, 1983.

[12] Hasemi, Y., "Thermal Modeling of Upward Wall Flame Spread, " Fire Safety Science - Proceedings of the 1st Int. Symposium., Editors. C. Grant and P. Pagni, (Hemisphere, Washington), pp. 361-369, Nov. 1985. 
[13] Ito, A. and Kashiwagi, T., "Characterization of Flame Spread over PMMA Using Holographic Interferometry Sample Orientation Effects, Combustion and Flame. 1987.

[14] Kulkarni, A. K., Kim, C. I., and Kuo, C. H., "Turbulent Upward Flame Spread for Burning Vertical Walls Made of Finite Thickness, NIST-GCR-91-597, May 1991.

[15] Quintiere, J., Harkleroad, M., and Hasemi, Y., "Wall Flames and Implications for Upward Flame Spread, " DOT/FAA/CT-85/2, June 1985.

[16] Orloff, L. and deRis, J., "Froude Modeling of Pool Fires, " 19th International Symposium on Combustion, The Combustion Institute, pp. $885,1983$.

[17] Ahmad, T. and Faeth, G. M., "Turbulent Wall Fires, " Colloquium on Fire and Explosion, 16th Symposium on Combustion, pp. 1149-1160, 1978.

[18] Dietenberger, M. A., "Description and Results of Furniture Fire Modules within FAST, " UDR-TR-87-29, University of Dayton Research Institute, January 1987.

[19] McCaffrey, B. J., "Momentum Implications for Buoyant Diffusion Flames," Combustion and Flame, Vol. 32, pp. 149-167, 1983

[20] Bard, S. and Pagni, P. M., "Spatial Variation of Soot Volume Fractions in Pool Fire Diffusion Flames, " presented at 1st International Symposium on Fire Safety Science, NBS, Gaithersburg, MD, October 7-11, 1985.

[21] Cetegen, B. M., Zukowski, E. E., and Kubota, T., "Entrainment and Flame Geometry of Fire Plumes, " California Institute of Technology, NBS Grant G89014, Aug. 1982.

[22] Hasemi, Y., "Thermal Modeling of Upward Wall Flame Spread," Fire Safety Science Proceedings of the First International Symposium, pp. 87-96, Nov. 1985.

[23] Siegal and Howell, eds, Thermal Radiation Heat Transfer, The Engineering Treatment of Gas Radiation in Enclosures, Ch. 17, Hemisphere Publishing Company (1981).

[24] Hottel, H. C. and Sarofim, A. F., "Radiative Transfer," McGraw-Hill, Inc., New York, 1967

[25] Orloff, L., "Simplified Radiation Modeling of Pool Fires," FRMC J. I. OEIEO .BU, RC80-8T-9, April, 1980. 
[26] Dayan, A. and Tien, C. L., "Radiant Heating from a Cylindrical Fire Column," Combustion Science and Technology, Vol. 9, pp. 41-47, 1974.

[27] Modak, A. T., "Thermal Radiation from Pool Fires," FMRC \# 22361-5, August, 1976.

[28] Jones, W.W and Forney, G.P., Improvement in Predicting Smoke Moevement in Compartmented Structures, Fire Safety Journal 21, 269 (1993).

[29] Dietenberger, Heat Release, V. Babarauskas, Ed. and The Fire Safety Journal (in press).

[30] Dietenberger, M. A., "Technical Reference and Guide for FAST/FFM Version 3, " NIST-GCR-91-589, 1991.

[31] Dietenberger, M. A., "A Validated Furniture Fire Model with FAST, " NISTGCR-89-564, 1989. 


\section{APPENDIX A: Sample Input Database Files}

This example is for a single compartment with $12.0 \times 4.0 \times 3.0 \mathrm{~m}$ dimensions and $3.8 \times 2.9 \times 0.02 \mathrm{~m}$ burning wall of combustible material (HO/FRPU). The door is partially opened and the fire is constrained.

\section{A.1 Wall Data Input File to Fast (WALL.DAT)}

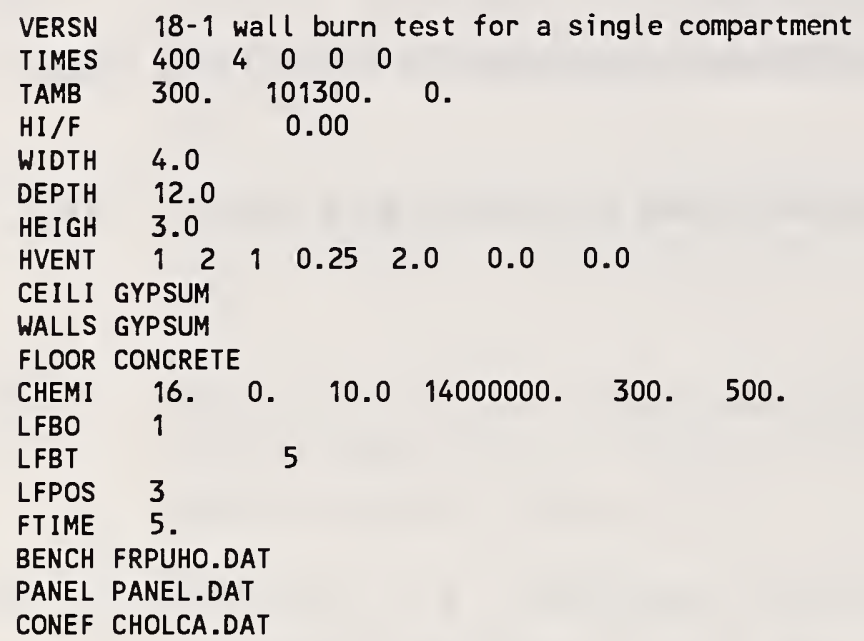

\section{A.2 Panel Database File as Input (PANEL.DAT)}

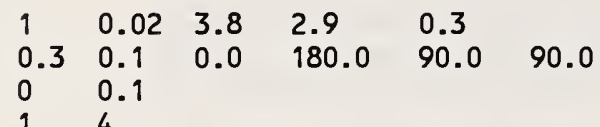

\section{A.3 Bench Database File as Input (FRPUHO.DAT)}

\begin{tabular}{|c|c|c|c|c|c|c|}
\hline $\begin{array}{l}1.0 \\
0.720 \\
30.0 \\
1.2845 \\
0.25\end{array}$ & $\begin{array}{l}0.0 \\
0.001287 \\
1.342 \\
0.4 \\
0.146\end{array}$ & $\begin{array}{c}0.19 \\
0.015 \\
0.6328 \\
700.0 \\
0.121\end{array}$ & $\begin{array}{c}711.3 \\
711.3 \\
5300 . \\
9.82 \\
3\end{array}$ & $\begin{array}{c}22.5 \\
1 \\
0.0\end{array}$ & $\begin{array}{l}0.019 \\
1 \\
1250 .\end{array}$ & $0^{0.1}$ \\
\hline
\end{tabular}




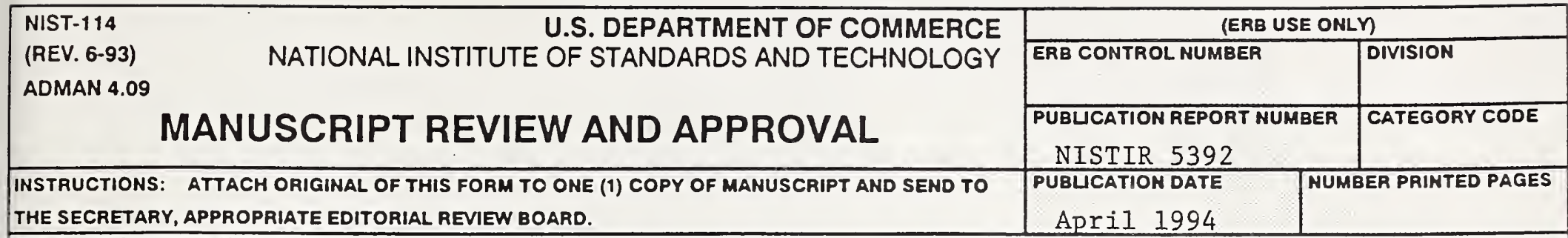

THE SECRETARY, APPROPRIATE EDITORIAL REVIEW BOARD.

TITLE AND SUBTITLE (CITE IN FULL)

Calculating Flame Spread on Horizontal and Vertical Surfaces

\begin{tabular}{|c|c|}
\hline CONTRACT OR GRANT NUMBER & TYPE OF REPORT AND/OR PERIOD COVERED \\
\hline AUTHOR(S) (LAST NAME, FIRST INITIAL, SECOND INITIAL) & PERFORMING ORGANIZATION (CHECK $(X)$ ONE BOX) \\
\hline Gama1 N. Ahmed & NIST/GAITHERSBURG \\
\hline Mark A. Dietenberger & NIST/BOULDER \\
\hline Walter W. Jones & JILA/BOULDER \\
\hline
\end{tabular}

LABORATORY AND DIVISION NAMES (FIRST NIST AUTHOR ONLY)

Building and Fire Research Laboratory, Fire Safety Engineering Division

SPONSORING ORGANIZATION NAME AND COMPLETE ADDRESS (STREET, CITY, STATE, ZIP)

\section{ROPOSED FOR NIST PUBLICATION}

JOURNAL OF RESEARCH (NIST JRES)

J. PHYS. \& CHEM. REF. DATA (JPCRD)

HANOBOOK (NIST HB)

SPECIAL PUBUCATION (NIST SP)

TECHNICAL NOTE (NIST TN)

ROPOSED FOR NON-NIST PUBLICATION (CITE FULYY

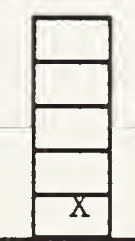

MONOGRAPH (NIST MN)

NATL STD. REF. DATA SERIES (NIST NSRDS)

FEDERAL INF. PROCESS. STDS. (NIST FIPS)

UST OF PUBLICATIONS (NIST LP)

NIST INTERAGENCY/INTERNAL REPORT (NISTIR)

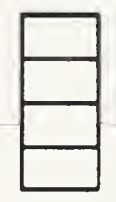

LETTER CIRCULAR

BUILDING SCIENCE SERIES

PAODUCT STANDARDS

OTHER

\section{PUBLSHING MEDIUM}

PAPER

DISKETTE (SPECIFY)

OTHER (SPECIFY)

SUPPLEMENTARY NOTES

ABSTRACT (A 2000-CHARACTER OR LESS FACTUAL SUMMARY OF MOST SIGNIFICANT INFORMATION. IF DOCUMENT INCLUDES A SIGNIFICANT BIBLIOGRAPHY

PR LTERATURE SURVEY, CITE IT HERE. SPELL OUT ACRONYMS ON FIRST REFERENCE.) (CONTINUE ON SEPARATE PAGE, IF NECESSARY.)

The flame spread model described in this paper is a new algorithm which provides the capability to calculate a self-consistent fire based substantually on bench scale fire data. The flame spread model simulates object fire growth and burnout of a slab in a room and produces acceptable predictions of the spread of fire, smoke and production of both toxic and nontoxic gases. The purpose of the flame spread model is to allow a fire to grow realistically, possibly making a hole in the material surface. This is one mechanism for barrier penetration. The algorithm is based on empirical data, gathered from standard test apparatus, including the Cone Calorimeter and the LIFT (lateral ignition flame spread test method). By basing the pyrolysis on test methods, we avoid the practical difficulties associated with an explicit calculation of radiation blocking and material charring. The objective of including the flame spread model is to predict the accelerative growth of a fire from ignition to a peak value and then the gradual termination normally seen in a fire. The intent of the project was to develop an algorithm which could be utilized in a complete model of a fire in a building. The three-dimensional aspects of the flame spread model include: first, panels made of combustible materials with different thicknesses and at various orientations; second, flames of two basic types, pool fire and purely wall fire; third, a radiation heat exchange between objects, flames, and gases. The pool fire has a flame spreading polygon on a horizontal panel and the wall fire is used either for inclined or vertical panels.

KEY WORDS (MAXIMUM 9 KEY WORDS; 28 CHARACTERS AND SPACES EACH; ALPHABETICAL ORDER; CAPITAUZE ONLY PROPER NAMES) computer algorithm; flame spread; fire model; zorie model; test methods

\section{AVAILABIUTY}

\begin{tabular}{|l}
\hline \\
\hline
\end{tabular}

UNUMITED

FOR OFFICIAL DISTRIBUTION - DO NOT RELEASE TO NTIS

ORDER FROM SUPERINTENDENT OF DOCUMENTS, U.S. GPO, WASHINGTON, DC 20402

ORDER FROM NTIS, SPRINGFIELD, VA 22161
NOTE TO AUTHOR(S): "IF YOU DO NOT WISH THIS MANUSCRIPT ANNOUNCED BEFORE PUBUCATION, PLEASE CHECK HERE. 


